Running Head: Need Supportive and Need Thwarting Interpersonal Behaviors

\title{
Refining the Assessment of Need Supportive and Need Thwarting Interpersonal Behaviors Using the Bifactor Exploratory Structural Equation Modeling Framework
}

\author{
István Tóth-Király ${ }^{1,2}$, Alexandre J.S. Morin ${ }^{1}$, Nicolas Gillet ${ }^{3}$, Beáta Bőthe ${ }^{4}$, Lindsey Nadon ${ }^{1}$, Adrien \\ Rigó $^{2}$, Gábor Orosz ${ }^{2}$ \\ ${ }^{1}$ Substantive-Methodological Synergy Research Laboratory, Department of Psychology, Concordia \\ University, Canada \\ ${ }^{2}$ Institute of Psychology, Eötvös Loránd University, Budapest, Hungary \\ ${ }^{3}$ Département de Psychologie, Université de Tours, France \\ ${ }^{4}$ Département de Psychologie, Université de Montréal, Canada
}

Acknowledgements: The first author was supported in the preparation of the manuscript by a Horizon Postdoctoral Fellowship from Concordia University and by the ÚNKP-17-3 New National Excellence Program of the Ministry of Human Capacities from Eötvös Loránd University. The second author was supported by a grant from the Social Science and Humanity Research Council of Canada (435-2018-0368). The fourth author was supported by a postdoctoral fellowship from the SCOUP Team - Sexuality and Couples - Fonds de recherche du Québec, Société et Culture. The seventh author was supported by the Hungarian Research Fund (NKFI FK 124225). The previous version of this paper was written while the first author was doing his $\mathrm{PhD}$ studies at Eötvös Loránd University.

Conflict of interest: All authors declare that they have no conflict of interest.

\section{Corresponding author:}

István Tóth-Király, Substantive-Methodological Synergy Research Laboratory

Department of Psychology, Concordia University

7141 Sherbrooke W, Montreal, QC, Canada, H4B 1R6

E-mail.: tothkiralyistvan@gmail.com; istvan.toth-kiraly@ concordia.ca

This document is a pre-publication version of the following manuscript:

Tóth-Király, I., Morin, A.J.S., Gillet, N., Bőthe, B., Nadon, L., Rigó, A., \& Orosz, G. (In Press, Accepted: 28 May 2020). Refining the Assessment of Need Supportive and Need Thwarting Interpersonal Behaviors Using the Bifactor Exploratory Structural Equation Modeling Framework. Current Psychology. doi: $10.1007 / \mathrm{s} 12144-020-00828-8$

(C) 2020. This paper is not the copy of record and may not exactly replicate the final, authoritative version of the article published in Current Psychology. The final authenticated version is available online at https://doi.org/10.1007/s12144-020-00828-8 


\title{
Refining the Assessment of Need Supportive and Need Thwarting Interpersonal Behaviors Using the Bifactor Exploratory Structural Equation Modeling Framework
}

\begin{abstract}
The present research assessed the psychometric multidimensionality and criterion-related validity the Interpersonal Behaviours Questionnaire using the bifactor-exploratory structural equation modeling framework. Study 1 relied on a sample of 772 participants, and supported the superiority of a bifactor-ESEM representation compared to alternative representations. Ratings of need supportive and thwarting behaviors simultaneously reflected a global overarching need nurturing behaviors construct (rather than two separate need-supportive and need-thwarting behaviours), which co-existed with six specific dimensions (autonomy, competence, and relatedness need supportive and thwarting behaviors). These results were replicated in a second independent sample of 742 participants and across gender. Our findings supported the criterionrelated validity of interpersonal behaviors in relation to positive affect, negative affect, and need fulfillment across samples and genders. We finally discuss the theoretical and practical implications of relying on the bifactor-ESEM framework when investigating need supportive and thwarting interpersonal behaviors.
\end{abstract}

Keywords: bifactor; exploratory structural equation modeling (ESEM); Interpersonal Behaviours Questionnaire (IBQ); need support and thwarting; Self-Determination Theory (SDT) 
The satisfaction and frustration of individuals' basic psychological needs are important drivers of motivation, performance, and psychological functioning across various spheres of life (Ryan \& Deci, 2017). Self-determination theory (SDT; Deci \& Ryan, 2000) posits that the satisfaction of the needs for autonomy (i.e., experiencing that one's actions are the result of volition and choice ), competence (i.e., experiencing efficiency and mastery when interacting with the environment), and relatedness (i.e., feeling a sense of social belonging with others) is a core driver of self-determined goal-directed behaviors. In contrast, the frustration of these needs leads to negative outcomes such as ill-being and distress (Bartholomew, Ntoumanis, Ryan, \& Thøgersen-Ntoumani, 2011b; Vansteenkiste \& Ryan, 2013). To understand how these needs can be satisfied or frustrated among individuals, one needs to consider the need supportive and thwarting characteristics of their environments (Ryan \& Deci, 2017).

Despite the recognition that a complete assessment of need-supportive and need-thwarting behaviors should tap into the three needs for autonomy, competence, and relatedness (Rocchi, Pelletier, Cheung, Baxter, \& Beaudry, 2017a; Rocchi, Pelletier, \& Desmarais, 2017b), research has never formally tested whether these behaviors are perceived in a more holistic manner as one (global need nurturing behaviors) or two (global need support and thwarting behaviors) overarching dimension(s). This global approach is supported by the observation of high positive correlations among ratings of autonomy, competence, and relatedness need supportive (e.g., Rocchi et al., 2017a, 2017b) and need thwarting (e.g., Myers, Martin, Ntoumanis, Celimli, \& Bartholomew, 2014; Rocchi et al., 2017a, 2017b) behaviors, as well as of moderately high negative correlations among ratings of need supportive and thwarting behaviors (Rocchi et al., 2017a, 2017b). Past research has also supported the presence of one global dimension underlying ratings of autonomy, competence, and relatedness need thwarting or need supportive behaviors in the sport area (Myers et al., 2014; Stenling, Ivarsson, Hassmén, \& Lindwall, 2015). However, research also reveals differentiated relations between external criteria and these six behavioral dimensions (autonomy, competence, and relatedness supportive and thwarting behaviors) (Rocchi et al., 2017a, 2017b).

More specifically, these observations raise important questions related to: (a) whether need-supportive and need-thwarting behaviors are better represented by one (i.e., need nurturing behaviors) or two (i.e., separate need-support and need-thwarting dimensions) global dimension(s); (b) whether specific needsupportive and need-thwarting behaviors retain specificity beyond the assessment of these overarching constructs; and (c) whether these overarching constructs exist as global entities including specificities mapped by the six behavioral dimensions, or whether these behaviors reflect distinct, yet correlated dimensions without a common core (Morin, Boudrias et al., 2016, 2017). The present study was specifically designed to address these questions while focusing on participants' responses to the recently developed Interpersonal Behaviours Questionnaire (IBQ), a questionnaire specifically developed to assess autonomy, relatedness, and competence need supportive and thwarting behaviors across various domains (Rocchi et al., 2017a, 2017b; Rodrigues, Pelletier, Neiva, Teixeira, \& Monteiro, 2019).

\section{Construct-Relevant Psychometric Multidimensionality}

Morin and colleagues (Morin, Arens, \& Marsh, 2016; Morin, Boudrias et al., 2016, 2017) note that construct-relevant psychometric multidimensionality needs to be specifically modelled when conceptuallyrelated constructs are assessed within an instrument, as is the case for measures of such as competence, autonomy, and relatedness supportive and thwarting behaviors. Construct-relevant psychometric multidimensionality refers to the idea that item ratings might be reliably associated with more than one latent construct. When ignored in confirmatory factor analysis (CFA), these additional associations have been shown to result in biased structural parameter estimates (Asparouhov, Muthén, \& Morin, 2015; Mai, Zhang, \& Wen, 2018; Morin, Arens et al., 2016).

Coexisting Global and Specific Constructs. A first form of construct-relevant psychometric multidimensionality that is relevant to the measure of need supportive and thwarting behaviors is related to the simultaneous assessment of global and specific constructs. When considering whether need supportive and need thwarting interpersonal behaviors are best represented as global constructs (Bartholomew, Ntoumanis, Ryan, Bosch, \& Thøgersen-Ntoumani, 2011a; Myers et al., 2014) or as conceptually-distinct constructs (Rocchi et al., 2017a, 2017b), a third option exists according to which interpersonal behaviors might exist as one or two global entities reflecting commonalities among ratings of autonomy, competence, 
and relatedness supportive and thwarting behaviors, which themselves may include specificity unexplained by these global entities (S-factors). In the sport area, results tentatively support the idea that ratings of autonomy, competence, and relatedness supportive behaviors are conceptually-related dimensions of a global need supportive behaviors construct, and that ratings of autonomy, competence, and relatedness thwarting similarly can be taken to reflect a global need thwarting behaviors construct (Myers et al., 2014; Pulido, Sánchez-Oliva, Leo, Sánchez-Cano, \& García-Calvo, 2018; Stenling et al., 2015). However, questions remain as to whether sufficient specificity exists in the three behavioral dimensions once the global construct is accounted for, and whether one or two global constructs are required to reflect the full spectrum of need supportive and thwarting behaviors. Higher-order factor models and bifactor models can both be used to achieve a proper disaggregation of this global/specific nature of need supportive and thwarting behaviors. However, the greater flexibility of bifactor models, which rely on the estimation of direct relations between the latent factors and item ratings, has led to recent recommendations of their superiority (Morin, Arens et al., 2016; Reise, 2012).

Conceptually-Related Constructs. A second form of construct-relevant psychometric multidimensionality that is relevant to the measure of need supportive and thwarting behaviors emerges from the imperfect nature of items which typically are found to be partially associated with non-target constructs (Morin, Arens, et al., 2016). This type of multidimensionality is best taken into account via exploratory factor analyses (EFA), in which cross-loadings are allowed between items and non-target constructs. The newly developed exploratory structural equation modeling (ESEM; Marsh, Morin, Parker, \& Kaur, 2014) framework represents the combination of EFA, CFA and structural equation modeling, providing a way to account for this type of multidimensionality across a broader range of model, including bifactor representations (Morin, Arens, et al., 2016). Interestingly, the recent study of Bhavsar et al. (2019) supported the added value of ESEM with respect to athletes' perceptions of their coaches' interpersonal behaviors.

Current Research Evidence for Multidimensionality. Research centered on need supporting and thwarting behaviors is scarcer outside of Rocchi et al.'s (2017a, 2017b) validation studies. When we look at research evidence related to ratings of need supportive and thwarting behaviors, Myers et al. (2014) first showed that the structure of athletes' ratings of the need thwarting behaviors present in their sport followed a bifactor-ESEM representation including an overarching need thwarting G-factor co-existing with welldefined S-factors related to the specific needs for autonomy competence, and relatedness (behavioral imbalance). These results have been replicated by Stenling et al. (2015). To our knowledge, only Pulido et al. (2018) examined the representation of coaches' interpersonal styles using a measure combining need supportive and thwarting behaviors. Although these authors found support for a hierarchical-ESEM structure including two higher-order factors, they failed to consider the more realistic bifactor-ESEM alternative and whether a single global factor could have been sufficient in capturing the globality of need nurturing behaviors, a possibility reinforced by their report of a high negative correlation between the global need supportive and thwarting factors $(r=-.673)$.

To our knowledge, this possibility has never been investigated specifically for combined measures of need supportive and thwarting behaviors, and never been investigated outside of the sport area. Still, one study systematically considered this possibility when considering participants' ratings of the satisfaction and frustration of their basic psychological needs in their life in general. In this study, Tóth-Király, Morin, Böthe, Orosz, and Rigó (2018) investigated the underlying structure of responses provided to the Basic Psychological Need Satisfaction and Frustration Scale (BPNSFS; Chen et al., 2015). Their results supported a global "need fulfillment" representation, incorporating a single G-factor, reflecting participants' global levels of need fulfillment, co-existing with six S-factors reflecting the degree to which participants felt imbalance in the degree to which each of their specific need was either satisfied or frustrated beyond their global levels of need satisfaction. Models with two global factors (global need satisfaction and frustration) resulted in overlapping factors, and were not supported by the data.

\section{Criterion-Related Validity}

Despite the interest of these pioneering studies on the structure of need supportive and thwarting behaviors, only Pulido et al. (2018) reported any evidence for the criterion related validity for the bifactor 
solution. Their results generally supported the criterion-related validity of the global need supporting and thwarting factors and participants' ratings of their levels of need satisfaction and frustration. Unfortunately, they did not report information regarding the relations involving the specific autonomy, competence, and relatedness need thwarting behaviors leaving as an open question whether the specificity associated with these dimensions, contributes to the prediction of need satisfaction/frustration over and above that afforded by the global factors.

Likewise, despite the fact that Rocchi et al. (2017a, 2017b) as well as Bhavsar et al. (2020) demonstrated the criterion-related validity of the IBQ in relation to need satisfaction and frustration, wellbeing, and motivation, these studies failed to disaggregate the variance explained by participants' global perceptions before looking at the specific role of autonomy, competence, and relatedness. The reliance on a bifactor-ESEM representation of need supportive/thwarting behaviors and of need satisfaction/frustration would make it possible to achieve a much cleaner disaggregation of the effects occurring at the global versus specific (behavioral imbalance) level. Importantly, this approach provides a way to take into account Sheldon and Niemiec's (2006; also see Dysvik, Kuvaas, \& Gagné, 2013) proposal that a complete understanding of psychological needs requires the simultaneous consideration of each need taken separately, but also of the degree to which they are aligned with one another, or the presence of imbalance in the degree to which all three needs are met.

The present study seeks to establish the criterion-related validity of participants' perceptions of the need supportive and need thwarting behaviors of people in their environment in relation to ratings of need satisfaction, need frustration, positive affect, and negative affect (Gillet, Fouquereau, Forest, Brunault, \& Colombat, 2012; Ryan \& Deci, 2017). Based on previous studies, we expected that global levels of need nurturing behaviors would be negatively associated with negative affect and need frustration, and positively associated with positive affect and need satisfaction. Over and above the effects of the global levels of need nurturing/supportive/thwarting behaviors, we also hypothesize that specific levels of autonomy, competence, and relatedness supportive and thwarting behaviors will present direct relations with the outcomes. However, lacking prior guidance, we leave as an open question whether these specific relations would reflect the incremental value of these behaviors (e.g., Sánchez-Oliva et al., 2017), or whether they will reflect need nurturing imbalance (e.g., Dysvik et al., 2013; Sheldon \& Niemiec, 2006).

\section{The Present Research}

In the present research, we rely on the bifactor-ESEM (e.g., Morin, Boudrias et al., 2016, 2017) framework to assess the underlying measurement structure of participants' ratings of the need supportive and thwarting behaviors of people in their environment. Following from Rocchi et al. (2017a, 2017b) and Tóth-Király et al. (2018), we also investigate the extent to which the optimal measurement structure of the IBQ would generalize across two distinct samples of participants, but also across genders. In addition, to examine whether there is value in considering specific levels of imbalance in the level of need supportive and thwarting behaviors over and above global levels of need nurturing/supportive/thwarting behaviors, we assess the criterion-related validity of these global and specific ratings in relation to various outcomes.

\section{Procedure and Participants}

\section{Methods}

Study 1. A total of 772 Hungarian participants (64.4\% female) with a mean age of 27.94 years $(S D=9.64)$ participated in this study. They reported their highest level of education as primary $(6.9 \%)$, secondary (64.9\%), and higher $(28.1 \%)$, and their place of residence as the capital city (42.9\%), county capitals $(13.9 \%)$, cities $(27.2 \%)$, and country (16.1\%). Participants were recruited between July 2017 and October 2017 via a number of mailing lists, online forums, and websites in order to gather a relatively large and diversified community sample of participants, in order to maximize the generalizability of our results. Before completing the questionnaires electronically, they were informed about the conditions of participation and had to explicitly indicate their consent. The study was conducted with the approval of the University Research Ethics Committee and in line with the Declaration of Helsinki.

Study 2. In the light of the recent replication crisis plaguing the different fields of psychology (e.g., Pashler \& Wagenmakers, 2012) and to test the potential generalizability of the results, a second sample of 742 Hungarian participants $(80.9 \%$ female) with a mean age of 26.49 years $(S D=7.27)$ participated in this 
Need Supportive and Need Thwarting Interpersonal Behaviors 5

study. These participants reported their highest level of education as primary (0.9\%), secondary (59.1\%), and higher $(40 \%)$, and their place of residence as the capital city $(46 \%)$, county capitals (15.6\%), cities (26.3\%), and country (12.1\%). This study followed the same procedures as Study 1 and participants completed the same set of questionnaires between November 2017 and February 2018.

\section{Measures}

Interpersonal Behaviours Questionnaire (IBQ). Participants completed the 24-item IBQ (Rocchi et al., 2017a). A context-general stem was used (i.e., "The people in my life...") and followed by the 24 items assessing the six following dimensions with 4 items each: autonomy support (e.g., “...support my decisions "; $\alpha=.882$ ) and thwarting (e.g., "...impose their opinions on me"; $\alpha=.885$ ), competence supportive (e.g., "...encourage me to improve my skills "; $\alpha=.857$ ) and thwarting (e.g., "...point out that I will likely fail"; $\alpha=.869$ ), and relatedness supportive (e.g., "... are interested in what I do"; $\alpha=.871$ ) and thwarting (e.g., "...do not connect with me"; $\alpha=.873)$. Respondents indicated their degree of agreement with the items on a sevenpoint scale ( $1=$ do not agree at all; $7=$ completely agree). The Hungarian version of this questionnaire was obtained by performing a translation/back-translation protocol (Beaton, Bombardier, Guillemin, \& Ferraz, 2000). Rocchi et al. (2017a) and Rodrigues et al. (2019) found support for the factorial validity, the scale score reliability, and the construct validity of the IBQ.

Basic Psychological Need Satisfaction and Frustration Scale (BPNSFS). Need fulfilment was assessed with the Hungarian version (Tóth-Király et al., 2018) of the BPNSFS (Chen et al., 2015). The BPNSFS includes 24 items measuring six dimensions with 4 items each: autonomy satisfaction $(\alpha=.767$; e.g., "I feel my choices express who I really am") and frustration ( $\alpha=.729$; e.g., "I feel pressured to do too many things"), relatedness satisfaction $(\alpha=.815$; e.g. "I feel close and connected with other people who are important to me") and frustration $(\alpha=.808$; e.g., "I have the impression that people I spend time with dislike me"), and competence satisfaction ( $\alpha=.827$; e.g., "I feel competent to achieve my goals") and frustration ( $\alpha=.849$; e.g., "I feel insecure about my abilities"). Participants rated each item on a five-point scale ( $1=$ not true at all for me; $5=$ very true for me). Findings reported by Tóth-Király et al. (2018) provided empirical support for the BPNSFS' factorial validity, generalizability across gender, and scale score reliability.

Positive and Negative Affect Scale (PANAS). Participants completed the 10-item Hungarian version (Gyollai, Simor, Köteles, \& Demetrovics, 2011) of the PANAS (Watson, Clark, \& Tellegen, 1988). This instrument is designed to assess positive ( 5 items; $\alpha=.767$; e.g., active, determined, or inspired) and negative ( 5 items; $\alpha=.725$; e.g., afraid, hostile, or nervous) affect. Each item was rated on a five-point scale (1=very slightly or not at all; $5=$ very much). Gyollai et al. (2011) found support for the factor structure and scale score reliability of the Hungarian version of the PANAS.

\section{Model Estimation}

\section{Analyses}

Statistical analyses were performed using the robust maximum likelihood (MLR) estimator implemented in Mplus 8 (Muthén \& Muthén, 1998-2017). The small amount of missing data at the item level (Study 1: 0\%; Study 2: $0 \%$ to $0.4 \%$ ) was handled with full information maximum likelihood (FIML) estimation procedures (Enders, 2010). Alternative representations of IBQ ratings were estimated in Study 1 and 2 applying the sequence proposed by Tóth-Király et al. (2018). These CFA, ESEM, and bifactor models are described in greater details in Table S1 of the online supplements.

\section{Measurement Invariance}

In order to assess the extent to which our results could be assumed to generalize across studies, we then proceeded to assess the measurement invariance of the most optimal solution. These tests were conducted in the following sequence (Millsap, 2011): (1) configural; (2) weak (loadings); (3) strong (intercepts); (4) strict (uniquenesses); (5) latent variance-covariance; and (6) latent means. With strong invariance, it becomes possible to combine the two samples for tests of invariance across gender.

\section{Criterion-Related Validity}

The criterion-related validity of the IBQ was finally assessed by incorporating participants' levels of need fulfillment and affect to the final retained model as outcomes of the need support and thwarting factors. Due to the complexity of these models, it was not possible to include these outcomes as latent variables. For 
this reason, preliminary measurement models were estimated for the outcomes before their incorporation into the predictive models as factor scores (Tables S4, S8, S9, S10) (Morin, Boudrias et al., 2016, 2017; Skrondal \& Laake, 2001). Tests of criterion-related validity were conducted in a multi-group framework to assess the extent to which the relations would generalize across studies, and gender groups in the following sequence: (a) predictions freely estimated; (b) regression slopes constrained to equality, (c) regression intercepts constrained to equality across groups; and (4) regression residuals constrained to equality.

\section{Model Evaluation}

We considered sample-size-independent goodness-of-fit indices for the assessment of model fit: The Comparative Fit Index (CFI), the Tucker-Lewis Index (TLI), and the Root Mean Square Error of Approximation (RMSEA) considering typical guidelines (Marsh, Hau, \& Grayson, 2005). Based on typical guidelines (Marsh et al., 2005), values greater than .90 and .95 for the CFI and TLI were respectively taken to reflect adequate and excellent fit, whereas values smaller than .08 or .06 for the RMSEA were respectively taken to indicate acceptable and excellent fit. Nested model comparisons for tests of measurement invariance and predictive similarity were compared via the examination of changes $(\Delta)$ in goodness-of-fit indices, where a decrease in CFI and TLI of .010 or higher or an increase in RMSEA of.015 or higher indicate a lack of invariance (Chen, 2007; Cheung \& Rensvold, 2002; Marsh et al., 2005). Reliability was assessed with McDonald's (1970) omega coefficient of composite reliability ( $\omega$; Morin, Myers, \& Lee, 2018).

Morin and colleagues (Morin, Arens et al., 2016) note that, because each alternative model considered here can absorb unmodelled multidimensionality, goodness-of-fit indices are not sufficient to guide the selection of the optimal solution. For this reason, goodness-of-fit information should always be complemented with a thorough examination of parameter estimates (e.g., factor loadings, cross-loadings, factor correlations) for all models that achieve a sufficient level of fit, starting with the comparison of CFA and ESEM solutions to verify whether cross-loadings should be incorporated (Morin, Arens, et al., 2016; Morin et al., 2018).

\section{Study 1: Measurement Models}

\section{Results}

The upper section of Table 1 presents the goodness-of-fit indices associated with all measurement models examined in Study 1. While the fit for most of the first-order CFA and ESEM solutions was unsatisfactory, the fit of the six-factor CFA and ESEM solutions was excellent. It is also interesting to note that the fit of the six-factor ESEM solution (Model 1.7) was substantially higher than that of the six-factor CFA solution (Model 1.6). Inspection of the standardized parameter estimates related to these solutions (see Table 2), revealed well-defined CFA factors but slightly weaker ESEM factors, mainly due to a subset of items (3-5-21) characterized by weak factor loadings on their target factors coupled by multiple crossloadings on multiple factors. Observing such a generalized undifferentiated pattern of cross-loading on multiple factors suggests that these items may tap into more global levels of need nurturing behaviors relative to their more specific a priori dimensions. With these exceptions, although the ESEM solution includes several statistically significant cross-loadings, none of the other items present a cross-loading large enough (e.g., $\geq .400)$ to suggest a problem in the definition of the factors. Only three other items $(1,12,15)$ presented high cross-loadings, all involving oppositely valenced factors. Furthermore, when looking at the factor correlations reported in Table 3, these were smaller in the ESEM solution than in the CFA solutions, in addition to having the appropriate direction (positive among similarly valenced factors, such as supportsupport, thwarting-thwarting and negative among factors with an opposite valence, such as supportthwarting).

These various considerations led us to retain the ESEM solution. This decision was reinforced when the bifactor solutions were examined, as these also demonstrated the superiority of relying on a bifactorESEM solution (relative to a bifactor-CFA solution) ${ }^{1}$. In selecting the optimal solution, a key question is

\footnotetext{
${ }^{1}$ For comparison purposes, we also estimated higher-order CFA and ESEM models matching the bifactor solutions. All of these higher-order models demonstrated worse model fit when compared to their bifactor counterparts, and models including two higher-order factors also converged on very high estimates of the correlation between the two higher-order factors. Fit indices associated with these higher-order models are provided in Table S11.
} 
whether two G-factors (Model 17) are better than a single G-factor (Model 15), given that both models demonstrated an almost identical level of model fit. An examination of parameter estimates of models including two G-factors is highly informative. In bifactor-CFA (Models 12 and 16), this correlation is high enough to suggest conceptual redundancies between the two G-factors. Despite the fact that these correlations are slightly reduced in bifactor-ESEM, they remain high enough to be problematic. In addition, these models also reveal weakly defined S-factors, large estimates of standard errors, and even negative residual estimates, suggestive of overparameterization and arguing against the inclusion of a second Gfactor to the model.

The six-factor ESEM solution and the bifactor-ESEM solution (six S-factors and one G-factor) resulted in an identical level of model fit. Examining the parameter estimates associated with the Model 15, reported in Table 4, provide further support to this bifactor solution. These results reveal a well-defined G-factor with positive loadings associated with the need supportive items and negative loadings associated with the need thwarting items. All need thwarting S-factors retained meaningful specificity. Finally, cross-loadings also decreased in magnitude relative to the six-factor ESEM solution. Based these observations, this bifactor-ESEM solution (Model 15) was retained.

\section{Study 2: Replicating the Final Measurement Structure}

Goodness-of-fit indices pertaining to the same set of measurement models estimated in Study 2 are presented in the bottom part of Table 1. Key results matching those reported for Study 1 are reported in Tables S2 and S3 of the online supplements and in the bottom section of Table 3. Examination of these results reinforce our prior conclusions about the superiority of the bifactor-ESEM solution that includes one G-factor and six S-factors (Model 15). To more precisely assess the replicability of Model 15 across studies, tests of measurement invariance were realized. These results (Table 5) supported the complete invariance of the bifactor-ESEM model across samples as none of the changes in fit indices ( $\triangle$ CFI, $\triangle T L I, \Delta R M S E A$ ) exceeded the recommended guidelines. These results support the replication of the bifactor-ESEM model across studies.

\section{Generalizability of the Results across Gender}

Since the complete measurement invariance of the final model was supported across studies, tests of measurement across gender were conducted on the combined sample to maximize sample size and statistical power. The results from these tests (Table 5) support the complete invariance of this solution across genders. Criterion-Related Validity

Results from the tests of predictive similarity for models incorporating the factor scores representing the outcomes (BPNSFS and PANAS) are reported in the bottom part of Table 5 and support the complete predictive similarity of these results across studies. Tests of predictive similarity conducted across genders also supported the similarity of the regression slopes and residuals across genders, but a change in TLI greater than .010 suggested that the regression intercepts were not fully equivalent across genders (Chen, 2007; Cheung \& Rensvold, 2002; Marsh et al., 2005). Examination of this second set of results revealed that the intercept of the competence satisfaction outcome was slightly lower among females, leading to a model of partial similarity that was supported by the data.

Parameter estimates from the analyses of criterion-related validity are reported in Table 6. Despite the lower level of specificity associated with the IBQ need supportive S-factors, they can still be considered to be fully reliable as they are defined as latent factors in this model. In contrast, all S-factors from the BPNSFS retained a satisfactory amount of specificity (Table S7). Consistent with SDT, the global need nurturing factor was positively associated with the global need fulfillment G-factor from the BPNSFS, as well as with the autonomy satisfaction, competence satisfaction, and relatedness satisfaction S-factors. This global need nurturing factor was also negatively associated with the autonomy frustration and relatedness frustration Sfactors of the BPNSFS, as well as with negative affect. This global need nurturing factor was also positively associated with positive affect. As expected, fewer statistically significant relations were found at the level of the IBQ S-factors.

Still, many of these additional associations matched SDT, with few exceptions: (a) specific imbalance in terms of relatedness support were positively associated with the competence and autonomy frustration Sfactors of the BPNSFS; (b) specific imbalance in terms of competence thwarting were positively associated 
with the autonomy satisfaction S-factor of the BPNSFS, whereas specific imbalance in terms of competence support were negatively related to the relatedness satisfaction S-factor of the BPNSFS; and (c) specific imbalance in autonomy thwarting were positively related to the relatedness satisfaction $S$-factor of the BPNSFS, whereas specific imbalance in autonomy support were positively related to the relatedness frustration S-factor of the BPNSFS. It is important to keep in mind these S-factors reflect the specificity that remains in participants' rating of autonomy support once their global perceptions regarding the extent to which their basic needs are nurtured by their environment are partialled out from these ratings. As such, these relations can be taken to directly reflect feelings of imbalance in the degree to which one need is supported relative to the others.

\section{Discussion}

The present series of two studies sought to propose an improved representation of the multidimensional structure of need supportive and need thwarting interpersonal behaviors ratings via the application of emerging bifactor-ESEM methodology (Morin, Arens, et al., 2016). In the present research, this framework allowed us to identify one overarching need nurturing G-factor underlying participants' responses to the IBQ (Rocchi et al., 2017a, 2017b), from six specific need supportive and need thwarting S-factors reflecting behavioral imbalance.

\section{The Structure of Need Nurturing Behaviors}

Our final solution revealed a well-defined need nurturing G-factor associated with positive factor loadings to the need supportive items and negative factor loadings to the need thwarting items. We also considered alternative models including two G-factors (need supportive behaviors and need nurturing behaviors). Although these alternative models achieved a satisfactory level of model fit, they resulted in highly correlated G-factors, thus calling the discriminant validity of these G-factors into question. These results thus argued in favor of a solution where a single G-factor was required to represent the globality of need nurturing behaviors. Thus, the seemingly divergent perspectives discussed in the introduction appeared to be complementary in nature: Perceptions of need supportive and need thwarting interpersonal behaviors appeared to be driven by a global need nurturing dimension, which co-existed with specific levels of imbalance in autonomy, competence, and relatedness need supportive and thwarting behaviors remaining unexplained by the global factor. At the global level, this representation matched that found by Tóth-Király et al. (2018) to underpin the structure of need fulfillment.

Still, the three need thwarting S-factors retained meaningful specificity over and above the G-factor, while the need supportive S-factors appeared to be weakly defined and to retain a very low level of specificity after the global levels of need nurturing perceptions were explicitly taken into account. Although not all S-factors need to retain a meaningful level of specificity in bifactor modeling (Morin et al., 2018), they show that participants' ratings of need supportive interpersonal behaviors mainly serve to define their global perceptions regarding their need nurturing interpersonal context. In contrast, although their ratings of need thwarting interpersonal behaviors also appear to contribute in a meaningful manner to their perceptions of their global need nurturing interpersonal context, they also appear to tap into something unique not explained by these global perceptions. This observation is not without evoking Herzberg's (1964) two factor theory of motivation in which motivators (environmental characteristics related to higher levels of satisfaction) where differentiated from hygiene factors (environmental characteristics whose absence leads to higher levels of dissatisfaction). Arguably, this representation of need-supportive and needthwarting interpersonal behaviors is an important contribution of the present research, and implies that researchers should consider the potential relevance of the bifactor-ESEM framework for their own research on need nurturing behaviors.

\section{Need Nurturing Behaviors, Need Fulfillment, and Affect}

A second key contribution of this study was to assess the criterion-related validity of the final solution, and most importantly to assess whether the specific levels of imbalance in need supportive and need thwarting would explain outcome variance beyond that explained by the global need nurturing G-factor. A first result from these analyses was that the relations between participants' IBQ ratings and their levels of need satisfaction, need frustration, and affect were clearly dominated by the effects of global need nurturing perceptions. In accordance with our expectations (Niemiec et al., 2006; Pulido et al., 2018; Rocchi et al., 
2017a), our results showed that participants' global perceptions of need nurturing behaviors presented positive relations with all of the desirable outcome measures considered in this study, and negative relations with most of the less desirable outcome measures. This global need nurturing factor also emerged as the strongest predictor of participants' scores on the more global outcomes (global need fulfillment, positive affect, and negative affect).

In contrast, the effects of specific imbalance in the perceptions of autonomy, competence, and relatedness supportive and thwarting behaviors were far less widespread, being typically limited to a much smaller number of outcomes. This observation is aligned with the observation that at least some of these Sfactors only included a limited amount of residual specificity. However, our results also revealed a substantial number of outcome associations located at the level of these specific factors, many of which were aligned with SDT, and all of whom could be explained by prior theoretical developments.

Specific Levels of Imbalance in Autonomy Need Thwarting Behaviors. Specific levels of imbalance in autonomy need thwarting behaviors were associated with lower levels of global need fulfillment, and with higher levels of autonomy need frustration and negative affect. Thus, when social agents (e.g., parents) are perceived as seeking to control or limit participants' freedom through pressure, intimidation, or rewards (Bartholomew, Ntoumanis, \& Thøgersen-Ntoumani, 2009), participants are more likely to experience (a) a global decrease in their levels of need fulfillment, (b) feelings of frustration of their needs for autonomy, and (c) more frequent negative affect.

Specific Levels of Imbalance in Relatedness Need Supportive and Thwarting Behaviors. Specific levels of imbalance in relatedness need supportive behaviors were associated with higher levels of relatedness need satisfaction and lower levels of relatedness need frustration. Interpersonal behaviors characterized by understanding, support, warmth, interest, and liking (Jones, Armour, \& Potrac, 2004) thus appeared beneficial in terms of increasing feelings of satisfaction and decreasing feelings of frustration of participants' needs for relatedness. Likewise, specific imbalance in relatedness need thwarting behaviors were related to lower levels of global need fulfillment and relatedness need satisfaction, as well as with higher levels of competence need frustration, relatedness need frustration, and negative affect. These findings are aligned with those from previous results revealing the negative impact of experiences of loneliness (i.e., frustrated relatedness needs) for a variety of maladaptive outcomes (Mellor, Stokes, Firth, Hayashi, \& Cummins, 2008; Valtorta, Kanaan, Gilbody, Ronzi, \& Hanratty, 2016).

Specific Levels of Imbalance in Competence Need Supportive and Thwarting Behaviors. Specific imbalance in competence need supportive behaviors were related to higher levels of global need fulfillment, competence need satisfaction, and positive affect, as well as with lower levels of competence need frustration. These results suggest that perceiving one's environment as being supportive to learning, able to provide constructive feedback, and as providing a positive impetus for improvement (Sheldon \& Filak, 2008) is conductive to positive affect, need fulfillment, and competence need satisfaction, and of lower levels of competence need frustration. The relations pertaining to specific imbalance in competence need supportive are particularly interesting, given that previous studies (Sánchez-Oliva et al., 2017) have also highlighted competence as an important predictor of outcomes over and above the need satisfaction Gfactor. The present results add to this earlier evidence by showing specific imbalance in competence need thwarting behaviors to be associated with higher levels of competence need frustration.

Need Imbalance. Some results appear counter-intuitive at first sight, such as the observation of positive relations between specific imbalance in autonomy need supportive behaviors and relatedness need frustration, between specific imbalance in autonomy need thwarting behaviors and relatedness need satisfaction, between specific imbalance in competence need thwarting behaviors and autonomy need satisfaction, and between specific imbalance in relatedness need supportive behaviors and autonomy/competence needs frustration, as well as of negative associations between specific levels of imbalance in competence need supportive behaviors and relatedness need satisfaction. These results need to be interpreted while keeping in mind the specific characteristics of the bifactor structure which has produced them. Although the G-factor reflecting global levels of need nurturing behaviors can directly be interpreted as ranging from a very low to a very high level of need nurturance, the interpretation of the Sfactors is not as straightforward. These $\mathrm{S}$-factors reflect what remains at the subscale level once the variance 
explained by global levels of need nurturing behaviors is partialled out. In other words, these S-factors can be taken to reflect discrepancies, or imbalance, in the degree to which participants' specific needs for autonomy, competence, and relatedness are supported or thwarted by the environment over and above this global level of need nurturance.

Previous research focusing on the satisfaction of the three psychological needs for autonomy, competence, and relatedness has also invoked the need to consider the possible impact of need imbalance (e.g., Dysvik et al., 2013; Sheldon \& Niemiec, 2006). For instance, Sheldon and Niemiec (2006) argued that to adequately understand the combined effects of need satisfaction, one needed to consider the extent to which the satisfaction of the three basic needs would be in alignment. The present study thus lends support to this hypothesis as applied to need nurturing behaviors, while simultaneously demonstrating how a bifactor-ESEM operationalization can be used to obtain a rigorous, yet simple, test of this hypothesis. For example, our results suggest that having strong relationships may impede one's autonomy or ability to express one's competence or to act in a fully autonomous manner.

\section{Limitations and Directions for Future Research}

The present study has its own limitations. First, we relied on self-report measures that can be influenced by self-report biases as well as by social desirability. Thus, we encourage researchers to consider more objective data (e.g., turnover) as well as informant-reported (e.g., supervisor) measures of performance. Second, although our treatment of need fulfillment and affect as outcomes was based on theoretical considerations, our design did not allow us to rule out the possibility of spurious associations, reciprocal influence, or reverse causality. Future longitudinal research should devote more attention to the identification of the true directionality of the associations among interpersonal behaviors and outcomes, as well as the developmental mechanisms involved in emergence, stability, and change in these various constructs.

\section{Practical and Methodological Implications}

Despite these limitations, our results suggest that need nurturing behaviors should be encouraged as these behaviors appeared to be positively associated with participants' autonomy, competence, and relatedness needs fulfillment, as well as with more positive affect. This conclusion ties in previous research showing that contributing to the creation of a social environment that satisfies the basic psychological needs for autonomy, competence, and relatedness through the provision of autonomy support, involvement, and structure leads to increased levels of need satisfaction and well-being, autonomous motivation, engagement, and prosocial behaviors (for an overview, see Ryan \& Deci, 2017). Autonomy support is related to the presence of alternative choices and the provision of a rationale for engaging in activities, as well as to the minimization of the use of controlling behaviors and evaluative communications. Involvement is present when the social agents are concerned with the person and understand his/her perspective. Finally, structure is the foundation of the need for competence and refers to perceived associations between how one behaves and what the result of these behaviors is going to be. An optimal structure is achieved by setting optimal, yet challenging tasks, explicit rules and directions for improvement, and clear guidelines.

Our results also add to accumulating evidence supporting the bifactor-ESEM framework for SDT research, providing researchers a way to obtain direct global estimates of participants quantity of selfdetermined motivation disaggregated from the specific levels of imbalance in the quality of their types of behavioral regulation (Howard et al., 2018; Litalien et al., 2017), as well as direct global and direct estimates of need fulfillment disaggregated from specific and non-redundant levels of imbalance in competence, autonomy, and relatedness need satisfaction and frustration (Gillet et al., 2017; Sánchez-Oliva et al., 2017; Tóth-Király et al., 2018). For research purposes, our study reinforces the need for SDT researchers to rely on similar methods when investigating these constructs. Our results suggest that failure to consider the global and specific components of need nurturing behaviors is likely to lead to erroneous conclusions that the need supporting and thwarting behaviors are relatively independent constructs. For applied researchers, this in turn could lead to biased practical recommendations. Our results also illustrate a reliable method that can be used to obtain a more precise and direct estimate of the global and specific components of need nurturing as bifactor models weight items based on their contribution to the global and specific factors simultaneously. To make this process seamless, as suggested by Perreira et al. (2018), automated scoring 
procedures could be developed, or the Mplus statistical package could be used to this end, which has the advantage of providing standardized measurements interpretable as a function of the sample mean and standard deviation, just like normed scores. Still, future studies should rely on more representative samples prior to developing scoring procedures.

Our results thus underscore the necessity to rely on the bifactor-ESEM framework to achieve a way to simultaneously consider the global need nurturing social context, properly disaggregated from the specific levels of imbalance in need supportive and thwarting behaviors to which participants are exposed. In doing so, our results demonstrated that need thwarting behaviors were something more than simply a lack of need nurturing, and retained a substantial amount of specificity over and above participants' global need nurturing perceptions. These findings are congruent with Vansteenkiste and Ryan's (2013) mention that the mere absence of need satisfaction does not necessarily equal the presence of need frustration. The present research demonstrated one potential way for more precisely assessing specific levels of imbalance in need thwarting effects. In addition, these results also suggest that need imbalance could play a more important role than previously expected (Dysvik et al., 2013).

Conflict of interest statement: The authors declare no conflict of interest

\section{References}

Asparouhov, T., Muthén, B., \& Morin, A.J.S. (2015). Bayesian Structural equation modeling with crossloadings and residual covariances. Journal of Management, 41, 1561-1577.

Bartholomew, K.J., Ntoumanis, N., Ryan, R.M., Bosch, J.A., \& Thøgersen-Ntoumani, C. (2011a). Selfdetermination theory and diminished functioning: The role of interpersonal control and psychological need thwarting. Personality and Social Psychology Bulletin, 37, 1459-1473.

Bartholomew, K.J., Ntoumanis, N., Ryan, R.M., \& Thøgersen-Ntoumani, C. (2011b). Psychological need thwarting in the sport context: Assessing the darker side of athletic experience. Journal of Sport and Exercise Psychology, 33, 75-102.

Bartholomew, K., Ntoumanis, N., \& Thorgenson-Ntoumani, C. (2009). A review of controlling motivational strategies from a self-determination theory perspective: Implications for sports coaches. International Review of Sport and Exercise Psychology, 2, 215-233.

Beaton, D.E., Bombardier, C., Guillemin, F., \& Ferraz, M.B. (2000). Guidelines for the process of crosscultural adaptation of self-report measures. Spine, 25, 3186-3191.

Bhavsar, N., Bartholomew, K.J., Quested, E., Gucciardi, D.F., Thøgersen-Ntoumani, C., Reeve, J., ... \& Ntoumanis, N. (2020). Measuring psychological need states in sport: Theoretical considerations and a new measure. Psychology of Sport and Exercise, 47.

Bhavsar, N., Ntoumanis, N., Quested, E., Gucciardi, D.F., Thøgersen-Ntoumani, C., Ryan, R.M., ... \& Bartholomew, K.J. (2019). Conceptualizing and testing a new tripartite measure of coach interpersonal behaviors. Psychology of Sport and Exercise, 44, 107-120.

Browne, M. (2001) An overview of analytic rotation in exploratory factor analysis. Multivariate Behavioral Research, 36, 111-150.

Chen, B., Vansteenkiste, M., Beyers, W., Boone, L., Deci, E.L., Van der Kaap-Deeder, J., ... \& Ryan, R.M. (2015). Basic psychological need satisfaction, need frustration, and need strength across four cultures. Motivation and Emotion, 39, 216-236.

Chen, F.F. (2007). Sensitivity of goodness of fit indexes to lack of measurement invariance. Structural Equation Modeling, 14, 464-504.

Cheung, G.W., \& Rensvold, R.B. (2002). Evaluating goodness-of-fit indexes for testing measurement invariance. Structural Equation Modeling, 9, 233-255.

Deci, E.L., \& Ryan, R.M. (2000). The" what" and" why" of goal pursuits: Human needs and the selfdetermination of behavior. Psychological inquiry, 11, 227-268.

Dysvik, A., Kuvaas, B., \& Gagné, M. (2013). An investigation of the unique, synergistic and balanced relationships between basic psychological needs and intrinsic motivation. Journal of Applied Social Psychology, 43, 1050-1064.

Enders, C. K. (2010). Applied missing data analysis. New York, NY: Guilford.

Gillet, N., Fouquereau, E., Forest, J., Brunault, P., \& Colombat, P. (2012). The impact of organizational 
Need Supportive and Need Thwarting Interpersonal Behaviors 12

factors on psychological needs and their relations with well-being. Journal of Business and Psychology, 27, 437-450.

Gillet, N., Morin, A.J.S., Huyghebaert, T., Burger, L., Maillot, A., Poulin, A., \& Tricard, E. (2017). University students' need satisfaction trajectories: A growth mixture analysis. Learning and Instruction. Early view doi: 10.1016/j.learninstruc.2017.11.003

Gyollai, Á., Simor, P., Köteles, F., \& Demetrovics, Zs. (2011). Psychometric properties of the Hungarian version of the original and the short form of the Positive and Negative Affect Schedule (PANAS). Neuropsychopharmacologia Hungarica, 13, 73-79.

Herzberg, F. (1964). The Motivation-Hygiene Concept and Problems of Manpower. Personnel Administrator, 27, 3-7.

Howard, J.L., Gagné, M., Morin, A.J.S., \& Forest, J. (2018). Using bifactor exploratory structural equation modeling to test for a continuum structure of motivation. Journal of Management, 44, 2638-2664.

Jones, R., Armour, K., \& Potrac, P. (2004). Sports coaching cultures. London: Routledge.

Litalien, D., Morin, A.J.S., Gagné, M., Vallerand, R.J., Losier, G.F., \& Ryan, R.M. (2017). Evidence of a continuum structure of academic self-determination: a two-study test using a bifactor-esem representation of academic motivation. Contemporary Educational Psychology, 51, 67-82.

Mai, Y., Zhang, Z., \& Wen, Z. (2018). Comparing exploratory structural equation modeling and existing approaches for multiple regression with latent variables. Structural Equation Modeling, 25, 737-479.

Marsh, H.W., Hau, K.-T., \& Grayson, D. (2005). Goodness of fit evaluation in structural equation modeling. In A. Maydeu-Olivares \& J. McArdle (Eds.), Contemporary psychometrics. A Festschrift for Roderick P. McDonald. Mahwah, NJ: Erlbaum.

Marsh, H., Morin, A.J.S., Parker, P., \& Kaur, G. (2014). Exploratory structural equation modeling: An integration of the best features of exploratory and confirmatory factor analysis. Annual Review of Clinical Psychology, 10, 85-110.

McDonald, R.P. (1970). Theoretical foundations of principal factor analysis, canonical factor analysis, and alpha factor analysis. British Journal of Mathematical \& Statistical Psychology, 23, 1-21.

Mellor, D., Stokes, M., Firth, L., Hayashi, Y., \& Cummins, R. (2008). Need for belonging, relationship satisfaction, loneliness, and life satisfaction. Personality \& Individual Differences, 45, 213-218.

Millsap, R.E. (2011). Statistical approaches to measurement invariance. New York: Taylor \& Francis.

Morin, A.J.S., Arens, A., \& Marsh, H. (2016). A bifactor exploratory structural equation modeling framework for the identification of distinct sources of construct-relevant psychometric multidimensionality. Structural Equation Modeling, 23, 116-139.

Morin, A.J.S., Boudrias, J.-S., Marsh, H.W., Madore, I., \& Desrumaux, P. (2016). Further reflections on disentengling shape and level effects in person-centered analyses: An illustration exploring the dimensionality of psychological health. Structural Equation Modeling, 23, 438-454.

Morin, A.J.S., Boudrias, J.-S., Marsh, H.W., McInerney, D.M., Dagenais-Desmarais, V., Madore, I., \& Litalien, D. (2017). Complementary variable- and person-centered approaches to the dimensionality of psychometric constructs: Application to psychological wellbeing at work. Journal of Business and Psychology, 32, 395-419.

Morin, A.J.S., Myers, N.D., \& Lee, S. (2018). Modern factor analytic techniques: Bifactor models, exploratory structural equation modeling (ESEM) and bifactor-ESEM. In G. Tenenbaum \& R.C. Eklund (Eds.), Handbook of sport psychology ( $4^{\text {th }}$ ed). Wiley.

Muthén, L.K., \& Muthén, B. (2017). Mplus user's guide ( $8^{\text {th }}$ ed.). Los Angeles, CA: Muthén \& Muthén.

Myers, N.D., Martin, J.J., Ntoumanis, N., Celimli, S., \& Bartholomew, K.J. (2014). Exploratory bifactor analysis in sport, exercise, and performance psychology: A substantive-methodological synergy. Sport, Exercise, and Performance Psychology, 3, 258-272.

Niemiec, C.P., Lynch, M.F., Vansteenkiste, M., Bernstein, J., Deci, E.L., \& Ryan, R.M. (2006). The antecedents and consequences of autonomous self-regulation for college: A self-determination theory perspective on socialization. Journal of Adolescence, 29, 761-775.

Pashler, H., \& Wagenmakers, E.J. (2012). Editors' introduction to the special section on replicability in psychological science. Perspectives on Psychological Science, 7, 528-530. 
Perreira, T.A., Morin, A.J.S., Hebert, M., Gillet, N., Houle, S., \& Berta, W. (2018). The short form of the Workplace Affective Commitment Multidimensional Questionnaire (WACMQ-S): A bifactor-ESEM approach among healthcare professionals. Journal of Vocational Behavior, 106, 62-83.

Pulido, J.J., Sánchez-Oliva, D., Leo, F.M., Sánchez-Cano, J., \& García-Calvo, T. (2018). Development and validation of Coaches' Interpersonal Style Questionnaire. Measurement in Physical Education and Exercise Science, 22, 25-37.

Reise, S.P. (2012). The rediscovery of bifactor measurement models. Multivariate Behavioral Research, 47, 667-696.

Rocchi, M., Pelletier, L., Cheung, S., Baxter, D., \& Beaudry, S. (2017a). Assessing need-supportive and need-thwarting interpersonal behaviours: The Interpersonal Behaviours Questionnaire (IBQ). Personality and Individual Differences, 104, 423-433.

Rocchi, M., Pelletier, L., \& Desmarais, P. (2017b). The validity of the Interpersonal Behaviors Questionnaire (IBQ) in sport. Measurement in Physical Education and Exercise Science, 21, 15-25.

Rodrigues, F., Pelletier, L., Neiva, H.P., Teixeira, D.S., Cid, L., \& Monteiro, D. (2019). Initial validation of the Portuguese version of the Interpersonal Behavior Questionnaire (IBQ \& IBQ-Self) in the context of exercise: Measurement invariance and latent mean differences. Current Psychology, 1-12.

Ryan, R.M., \& Deci, E.L. (2017). Self-determination theory. Basic psychological needs in motivation, development, and wellness. New York, NY: Guildford Press.

Sánchez-Oliva, D., Morin, A.J.S., Teixeira, P.J., Carraça, E.V., Palmeira, A.L., \& Silva, M.N. (2017). A bifactor-exploratory structural equation modeling representation of the structure of basic psychological needs at work scale. Journal of Vocational Behavior, 98, 173-187.

Sheldon, K.M., \& Filak, V. (2008). Manipulating autonomy, competence, and relatedness support in a game-learning context: New evidence that all three needs matter. British Journal of Social Psychology, 47, 267-283.

Sheldon, K.M., \& Niemiec, C.P. (2006). It's not just the amount that counts: Balanced need satisfaction also affects well-being. Journal of Personality \& Social Psychology, 91, 331-341.

Skrondal, A., \& Laake, P. (2001). Regression among factor scores. Psychometrika, 66, 563-575.

Stenling, A., Ivarsson, A., Hassmén, P., \& Lindwall, M. (2015). Using bifactor exploratory structural equation modeling to examine global and specific factors in measures of sports coaches' interpersonal styles. Frontiers in psychology, 6, 1303.

Tóth-Király, I., Morin, A.J.S., Bőthe, B., Orosz, G., \& Rigó, A. (2018). Investigating the multidimensionality of need fulfillment: A bifactor exploratory structural equation modeling representation. Structural Equation Modeling, 25, 267-286.

Valtorta, N.K., Kanaan, M., Gilbody, S., Ronzi, S., \& Hanratty, B. (2016). Loneliness and social isolation as risk factors for coronary heart disease and stroke: systematic review and meta-analysis of longitudinal observational studies. Heart, 102, 1009-1016.

Vansteenkiste, M., \& Ryan, R.M. (2013). On psychological growth and vulnerability: Basic psychological need satisfaction and need frustration as a unifying principle. Journal of Psychotherapy Integration, 23, 263-280.

Watson, D., Clark, L.A., \& Tellegen, A. (1988). Development and validation of brief measures of positive and negative affect. Journal of Personality and Social Psychology, 54, 1063-1070. 
Table 1

Goodness-of-Fit Statistics for the Models Estimated on the Interpersonal Behaviours Questionnaire

\begin{tabular}{|c|c|c|c|c|c|c|}
\hline Model & $\chi^{2}$ & $\mathrm{df}$ & CFI & TLI & RMSEA & RMSEA 90\% CI \\
\hline \multicolumn{7}{|l|}{ Study 1} \\
\hline Model 1.1. One-factor CFA $(\mathrm{Nu})$ & $2049.822 *$ & 252 & .788 & .767 & .096 & $.092-.100$ \\
\hline Model 1.2. Two-factor CFA (Su, Th) & $1385.568 *$ & 251 & .866 & .853 & .077 & $.073-.080$ \\
\hline Model 1.3. Two-factor ESEM (Su, Th) & $1378.734 *$ & 229 & .864 & .836 & .081 & $.077-.085$ \\
\hline Model 1.4. Three-factor CFA (A, C, R) & $1611.473^{*}$ & 249 & .839 & .822 & .084 & $.080-.088$ \\
\hline Model 1.5. Three-factor ESEM (A, C, R) & $721.785^{*}$ & 207 & .939 & .919 & .057 & $.052-.061$ \\
\hline Model 1.6. Six-factor CFA (A-Su, A-Th, C-Su, C-Th, R-Su, R-Th) & $594.143^{*}$ & 237 & .958 & .951 & .044 & $.040-.049$ \\
\hline Model 1.7. Six-factor ESEM (A-Su, A-Th, C-Su, C-Th, R-Su, R-Th) & $226.187 *$ & 147 & .991 & .982 & .026 & $.019-.033$ \\
\hline Model 1.8. B-CFA: Two S-factors ( $\mathrm{Su}, \mathrm{Th})$ and one G-factor $(\mathrm{Nu})$ & $1013.275^{*}$ & 228 & 907 & .888 & .067 & $.063-.071$ \\
\hline Model 1.9. B-ESEM: Two S-factors (S, Fr) and one G-factor (Nu) & $721.785^{*}$ & 207 & .939 & .919 & .057 & $.052-.061$ \\
\hline Model 1.10. B-CFA: Three S-factors (A, C, R) and one G-factor $(\mathrm{Nu})$ & $952.625^{*}$ & 228 & .914 & .896 & .064 & $.060-.068$ \\
\hline Model 1.11. B-ESEM: Three S-factors $(\mathrm{A}, \mathrm{C}, \mathrm{R})$ and one $\mathrm{G}$-factor $(\mathrm{Nu})$ & $405.083^{*}$ & 186 & .974 & .962 & .039 & $.034-.044$ \\
\hline Model 1.12. B-CFA: Three S-factors (A, C, R) and two G-factors (Su, Th) & $440.490 *$ & 227 & .975 & .969 & .035 & $.030-.040$ \\
\hline Model 1,13. B-ESEM: Three S-factors (A, C, R) and two G-factors (Su, Th) & $393.773 *$ & 182 & .975 & .962 & .039 & $.034-.044$ \\
\hline Model 1.14. B-CFA: Six S-factors (A-Su, A-Th, C-Su, C-Th, R-Su, R-Th) and one G-factor (Nu) & $851.961 *$ & 228 & .926 & .911 & .060 & $.055-.064$ \\
\hline Model 1.15. B-ESEM: Six S-factors (A-Su, A-Th, C-Su, C-Th, R-Su, R-Th) and one G-factor (Nu) & $193.618^{*}$ & 129 & .992 & .984 & .025 & $.018-.033$ \\
\hline Model 1.16. B-CFA: Six S-factors (A-Su, A-Th, C-Su, C-Th, R-Su, R-Th) and two G-factor (Su, Th) & $686.710^{*}$ & 227 & .946 & .934 & .051 & $.047-.056$ \\
\hline Model 1.17. B-ESEM: Six S-factors (A-Su, A-Th, C-Su, C-Th, R-Su, R-Th) and two G-factor (Su, Th) & $187.989 *$ & 122 & .992 & .982 & .026 & $.019-.034$ \\
\hline \multicolumn{7}{|l|}{ Study 2} \\
\hline Model 2.1. One-factor CFA (Nu) & $2061.123 *$ & 252 & .773 & .752 & .098 & $.094-.102$ \\
\hline Model 2.2. Two-factor CFA (Su, Th) & $1723.926 *$ & 251 & .815 & .797 & .089 & $.085-.093$ \\
\hline Model 2.3. Two-factor ESEM (Su, Th) & $1264.733 *$ & 229 & .870 & .844 & .078 & $.074-.082$ \\
\hline Model 2.4. Three-factor CFA (A, C, R) & $1376.721 *$ & 249 & .859 & .843 & .078 & $.074-.082$ \\
\hline Model 2.5. Three-factor ESEM (A, C, R) & $758.108^{*}$ & 207 & .931 & .908 & .060 & $.055-.065$ \\
\hline Model 2.6. Six-factor CFA (A-Su, A-Th, C-Su, C-Th, R-Su, R-Th) & $552.950 *$ & 237 & .960 & .954 & .042 & $.038-.047$ \\
\hline Model 2.7. Six-factor ESEM (A-Su, A-Th, C-Su, C-Th, R-Su, R-Th) & $250.609 *$ & 147 & .987 & .976 & .031 & $.024-.037$ \\
\hline Model 2.8. B-CFA: Two S-factors (Su, Th) and one G-factor $(\mathrm{Nu})$ & $966.991 *$ & 228 & .907 & .888 & .066 & $.062-.070$ \\
\hline Model 2.9. B-ESEM: Two S-factors (S, Fr) and one G-factor $(\mathrm{Nu})$ & $758.108^{*}$ & 207 & .931 & .908 & .060 & $.055-.065$ \\
\hline Model 2.10. B-CFA: Three S-factors (A, C, R) and one G-factor (Nu) & $645.920^{*}$ & 228 & .948 & .937 & .050 & $.045-.054$ \\
\hline Model 2.11. B-ESEM: Three S-factors $(\mathrm{A}, \mathrm{C}, \mathrm{R})$ and one $\mathrm{G}$-factor $(\mathrm{Nu})$ & $366.580^{*}$ & 186 & .977 & .966 & .036 & $.031-.042$ \\
\hline Model 2.12. B-CFA: Three S-factors (A, C, R) and two G-factors (Su, Th) & $479.256^{*}$ & 227 & .968 & .962 & .039 & $.034-.044$ \\
\hline Model 2.13. B-ESEM: Three S-factors (A, C, R) and two G-factors (Su, Th) & $325.929 *$ & 182 & .982 & .973 & .033 & $.027-.038$ \\
\hline Model 2.14. B-CFA: Six S-factors (A-Su, A-Th, C-Su, C-Th, R-Su, R-Th) and one G-factor (Nu) & $794.076^{*}$ & 228 & .929 & .914 & .058 & $.053-.062$ \\
\hline Model 2.15. B-ESEM: Six S-factors (A-Su, A-Th, C-Su, C-Th, R-Su, R-Th) and one G-factor (Nu) & $201.062 *$ & 129 & .991 & .981 & .027 & $.020-.035$ \\
\hline Model 2.16. B-CFA: Six S-factors (A-Su, A-Th, C-Su, C-Th, R-Su, R-Th) and two G-factor (Su, Th) & $761.047 *$ & 227 & .933 & .919 & .056 & $.052-.061$ \\
\hline Model 2.17. B-ESEM: Six S-factors (A-Su, A-Th, C-Su, C-Th, R-Su, R-Th) and two G-factor (Su, Th) & $205.495^{*}$ & 122 & .990 & .976 & .030 & $.023-.037$ \\
\hline
\end{tabular}

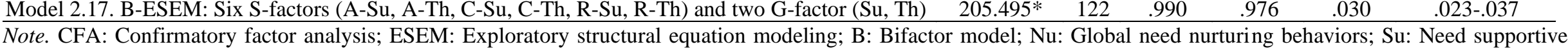
behaviors; Th: Need thwarting behaviors; A: Autonomy; C: Competence; R: Relatedness; G-factor: Global factor estimated as part of a bifactor model; S-factor: Specific factor estimated as part of a bifactor model; $\chi^{2}$ : Robust chi-square test of exact fit; df: Degrees of freedom; CFI: Comparative fit index; TLI: Tucker-Lewis index; RMSEA: Root mean square error of approximation; $90 \% \mathrm{CI}$ : $90 \%$ confidence interval of the RMSEA; $* p<0.01$. 
Table 2

Standardized Parameter Estimates from the Six-Factor CFA and ESEM Solutions in Study $1(N=772)$ : Interpersonal Behaviours Questionnaire

\begin{tabular}{|c|c|c|c|c|c|c|c|c|c|}
\hline & \multicolumn{2}{|c|}{ CFA } & \multirow{2}{*}{\multicolumn{7}{|c|}{ ESEM }} \\
\hline & Factor $(\lambda)$ & $\delta$ & & & & & & & \\
\hline \multicolumn{10}{|l|}{ Autonomy-support (A-Su) } \\
\hline Item 1 & $.695 * *$ & .517 & $.419 * *$ & $.162 *$ & -.011 & $-.382 * *$ & .074 & .010 & .455 \\
\hline Item 7 & $.883 * *$ & .221 & $.661 * *$ & $.106^{*}$ & .080 & $-.091 *$ & -.046 & -.065 & .208 \\
\hline Item 13 & $.861 * *$ & .259 & $.652 * *$ & .077 & $.158 * *$ & -.069 & -.056 & .001 & .241 \\
\hline Item 19 & $.816 * *$ & .335 & $.497 * *$ & $.169 * *$ & $.136^{*}$ & $-.179 * *$ & -.009 & .004 & .347 \\
\hline & .888 & & .799 & & & & & & \\
\hline \multicolumn{10}{|l|}{ Competence-support (C-Su) } \\
\hline Item 3 & $.683 * *$ & .533 & $.469 * *$ & $.272 * *$ & -.016 & $.166 * *$ & -.053 & $-.201 * *$ & .466 \\
\hline Item 9 & $.709 * *$ & .498 & .014 & $.652 * *$ & .183 & $-.129 * *$ & .068 & -.037 & .343 \\
\hline Item 15 & $.858 * *$ & .264 & .170 & $.436 * *$ & $.254 * *$ & .052 & $-.387 * *$ & $.147 * *$ & .230 \\
\hline Item 21 & $.841 * *$ & .293 & $.229 * *$ & .213 & $.364 * *$ & -.003 & $-.434 * *$ & $.198 * *$ & .224 \\
\hline & .857 & & & .662 & & & & & \\
\hline \multicolumn{10}{|l|}{ Relatedness-support (R-Su) } \\
\hline Item 5 & $.700 * *$ & .510 & $.267 * *$ & $.359 * *$ & 127 & $.133 * *$ & -.044 & $-.208 * *$ & .453 \\
\hline Item 11 & $.833 * *$ & .306 & .007 & $.346^{* *}$ & $.444 * *$ & $-.108 *$ & $.128^{*}$ & $-.261 * *$ & .283 \\
\hline Item 17 & $.822 * *$ & .325 & .102 & .063 & $.620 * *$ & .003 & .049 & $-.247 * *$ & .274 \\
\hline Item 23 & $.816 * *$ & .334 & $.186^{* *}$ & .108 & $.501 * *$ & $-.085^{*}$ & .079 & $-.197 * *$ & .327 \\
\hline$\omega$ & .872 & & & & .682 & & & & \\
\hline \multicolumn{10}{|l|}{ Autonomy-thwarting (A-Th) } \\
\hline $\begin{array}{l}\text { Item } 2 \\
\text { Item } 8\end{array}$ & $\begin{array}{l}.732 * * \\
815 * *\end{array}$ & .464 & -.094 & -.010 & .002 & $.729 * *$ & .014 & -.039 & .411 \\
\hline Item 8 & $.815 * *$ & .335 & $-.115^{*}$ & -.041 & .038 & $.694 * *$ & $.076^{*}$ & .037 & .322 \\
\hline Item 14 & $.856 * *$ & .266 & .003 & -.027 & -.089 & $.703 * *$ & $.146^{* *}$ & .046 & .259 \\
\hline Item 20 & $.805 * *$ & .353 & -.271 & $.155^{* *}$ & -.016 & $.528 * *$ & $.171 * *$ & .105 & .353 \\
\hline & .879 & & & & & .840 & & & \\
\hline \multicolumn{2}{|l|}{ Competence-thwarting (C-Th) } & 436 & -074 & $-.169 * *$ & $143 *$ & $150 * *$ & $.520 * *$ & $142 *$ & 425 \\
\hline Item 10 & $.811 * *$ & .343 & .012 & -.088 & -.018 & $.240 * *$ & $.433 * *$ & $.249 * *$ & 359 \\
\hline Item 16 & $.812 * *$ & .341 & .073 & -.161 & -.019 & $.151 * *$ & $.617 * *$ & $.124 * *$ & .322 \\
\hline Item 22 & $.746 * *$ & .444 & -.105 & -.027 & .090 & $.107 *$ & $.512 * *$ & $.249 * *$ & .430 \\
\hline \multirow{2}{*}{\multicolumn{10}{|c|}{$\begin{array}{l}\omega \\
\text { Relatedness-thwarting (R-Th) }\end{array}$}} \\
\hline & & & & & & & & & \\
\hline Item 6 & $.760 * *$ & .422 & .064 & $-.252 * *$ & .011 & .065 & $.235 * *$ & $.508 * *$ & .371 \\
\hline Item 12 & $.779 * *$ & .393 & .055 & $.114^{*}$ & $-.328 * *$ & .120 & $.118 *$ & $.517 * *$ & .375 \\
\hline Item 18 & $.802 * *$ & .357 & -.054 & $.162 * *$ & $-.264 * *$ & .036 & .096 & $.629 * *$ & .321 \\
\hline Item 24 & $.841 * *$ & .293 & -.060 & .017 & -.088 & .017 & $.182 * *$ & $.664 * *$ & .285 \\
\hline$\omega$ & .874 & & & & & & & .799 & \\
\hline
\end{tabular}

Note. CFA: Confirmatory factor analysis; ESEM: Exploratory structural equation modeling; Su: Need supportive behaviors; Th: Need thwarting behaviors; A: Autonomy; C: Competence; R: Relatedness; $\lambda$ : Factor loading; $\delta$ : Item uniqueness; $\omega$ : Model-based omega composite reliability; Target factor loadings are in bold; $* p<.05 ; * * p<.01$ 
Need Supportive and Need Thwarting Interpersonal Behaviors 16

Table 3

Latent Factor Correlations from the Six-Factor CFA (Under the Diagonal) and ESEM (Over the Diagonal) Solutions in Study 1 ( $N=772)$ and 2 ( $N$ =742): Interpersonal Behaviours Questionnaire

\begin{tabular}{|c|c|c|c|c|c|c|}
\hline & $\mathrm{A}-\mathrm{Su}$ & $\mathrm{C}-\mathrm{Su}$ & $\mathrm{R}-\mathrm{Su}$ & A-Th & C-Th & R-Th \\
\hline \multicolumn{7}{|l|}{ Study 1} \\
\hline Autonomy-support (A-Su) & - & .625 & .584 & -.458 & -.495 & -.425 \\
\hline Competence-support (C-Su) & .921 & - & .448 & -.364 & -.374 & -.449 \\
\hline Relatedness-support (C-Su) & .852 & .868 & - & -.297 & -.450 & -.518 \\
\hline Autonomy-thwarting (A-Th) & -.742 & -.634 & -.610 & - & .517 & .509 \\
\hline Competence-thwarting (R-Th) & -.739 & -.799 & -.687 & .839 & - & .416 \\
\hline Relatedness-thwarting (C-Th) & -.694 & -.694 & -.849 & .713 & .816 & - \\
\hline Study 2 & $\mathrm{~A}-\mathrm{Su}$ & $\mathrm{C}-\mathrm{Su}$ & $\mathrm{R}-\mathrm{Su}$ & A-Th & C-Th & $\mathrm{R}-\mathrm{Th}$ \\
\hline Autonomy-support (A-Su) & - & .659 & .564 & -.554 & -.608 & -.446 \\
\hline Competence-support (C-Su) & .921 & - & .415 & -.338 & -.428 & -.539 \\
\hline Relatedness-support (C-Su) & .832 & .890 & - & -.300 & -.498 & -.567 \\
\hline Autonomy-thwarting (A-Th) & -.713 & -.620 & -.566 & - & .573 & .401 \\
\hline Competence-thwarting (R-Th) & -.735 & -.836 & -.709 & .755 & - & .439 \\
\hline Relatedness-thwarting (C-Th) & -.712 & -.759 & -.929 & .580 & .729 & - \\
\hline
\end{tabular}

Note. CFA: Confirmatory factor analysis; ESEM: Exploratory structural equation modeling; Su: Need supportive behaviors; Th: Need thwarting behaviors; A: Autonomy; C: Competence; R: Relatedness; All correlations are significant at $p<.01$; These correlations involve latent factors for which the scale was set using the referent indicator approach, and thus having a mean of 0 and a SD of 1 . 
Table 4

Standardized Parameter Estimates from the Bifactor-ESEM Solution Including Six S-Factors and One G-Factor in Study 1 (N = 772):

Interpersonal Behaviours Questionnaire

\begin{tabular}{|c|c|c|c|c|c|c|c|c|}
\hline & $\mathrm{Nu}(\lambda)$ & $\mathrm{A}-\mathrm{Su}(\lambda)$ & $\mathrm{C}-\mathrm{Su}(\lambda)$ & $\mathrm{R}-\mathrm{Su}(\lambda)$ & A-Th $(\lambda)$ & C-Th $(\lambda)$ & R-Th $(\lambda)$ & $\delta$ \\
\hline \multicolumn{9}{|l|}{ Autonomy-support (A-Su) } \\
\hline Item 1 & $.684 * *$ & .114 & -.050 & -.153 & $-.212 * *$ & $.190 * *$ & .096 & .403 \\
\hline Item 7 & $.823 * *$ & $.304 * *$ & .021 & .012 & -.009 & .059 & .067 & .223 \\
\hline Item 13 & $.776 * *$ & $.426 * *$ & .046 & $.129 * *$ & -.002 & -.012 & $.096 * *$ & .188 \\
\hline Item 19 & $.767 * *$ & $.213 * *$ & .037 & .003 & -.051 & $.107 * *$ & .086 & .343 \\
\hline & & .491 & & & & & & \\
\hline \multicolumn{9}{|l|}{ Competence-support (C-Su) } \\
\hline Item 3 & $.682 * *$ & $.151 *$ & -.075 & -.083 & $.224 * *$ & .104 & .028 & .437 \\
\hline Item 9 & $.731 * *$ & -.093 & -.115 & .140 & $.086 *$ & .104 & $.176 * *$ & .375 \\
\hline Item 15 & $.815 * *$ & -.012 & .238 & .008 & $.167 * *$ & -.074 & $.193 *$ & .209 \\
\hline Item 21 & $.781 * *$ & .093 & $.340 * *$ & .059 & .074 & -.119 & .118 & .229 \\
\hline & & & .321 & & & & & \\
\hline \multicolumn{9}{|l|}{ Relatedness-support (C-Su) } \\
\hline Item 5 & $.680 * *$ & .110 & -.121 & .202 & $.198 * *$ & -.035 & .051 & .428 \\
\hline Item 11 & $.756 * *$ & -.053 & -.087 & $.402 * *$ & .044 & $.095^{*}$ & -.082 & .239 \\
\hline Item 17 & $.705 * *$ & .061 & $.140 *$ & .335 & .094 & .123 & $-.248 * *$ & .282 \\
\hline Item 23 & $.732 * *$ & .079 & .093 & .262 & .032 & .147 & $-.165 * *$ & .331 \\
\hline$\omega$ & & & & .530 & & & & \\
\hline \multicolumn{9}{|l|}{ Autonomy-thwarting (A-Th) } \\
\hline Item 2 & $-.552 * *$ & .033 & .019 & $.119 *$ & $.537 * *$ & -.018 & -.010 & .391 \\
\hline Item 8 & $-.622 * *$ & -.026 & .085 & .013 & $.526 * *$ & $.126 * *$ & -.013 & .312 \\
\hline Item 14 & $-.670 * *$ & .046 & -.011 & .021 & $.513 * *$ & $.122 * *$ & .067 & .266 \\
\hline Item 20 & $-.633 * *$ & $-.153 * *$ & -.027 & .037 & $.436 * *$ & .155 & $.110 *$ & .348 \\
\hline & & & & & .755 & & & \\
\hline \multicolumn{9}{|l|}{ Competence-thwarting (R-Th) } \\
\hline Item 4 & $-.652 * *$ & .034 & -.017 & .133 & $.122 * *$ & $.339 * *$ & .006 & .426 \\
\hline Item 10 & $-.703 * *$ & .063 & -.035 & .060 & $.185 * *$ & $.278 * *$ & $.156 * *$ & .360 \\
\hline Item 16 & $-.687 * *$ & .076 & $-.119 * *$ & .044 & $.122 * *$ & $.415 * *$ & .058 & .316 \\
\hline Item 22 & $-.638 * *$ & -.010 & -.036 & .088 & $.122 * *$ & $.351 * *$ & $.126 *$ & .430 \\
\hline & & & & & & .559 & & \\
\hline \multicolumn{9}{|l|}{ Relatedness-thwarting (C-Th) } \\
\hline Item 6 & $-.705 * *$ & .144 & $.163 * *$ & -.041 & .015 & .176 & $.221 * *$ & .373 \\
\hline Item 12 & $-.622 * *$ & .079 & -.044 & $-.138 * *$ & $.089 *$ & .033 & $.459 * *$ & .367 \\
\hline Item 18 & -.639** & .015 & -.004 & -.084 & .032 & .010 & $.535 * *$ & .297 \\
\hline Item 24 & $-.702 * *$ & .034 & .117 & -.074 & .023 & $.128 *$ & $.424 * *$ & .290 \\
\hline$\omega$ & .973 & & & & & & .669 & \\
\hline
\end{tabular}

Note. CFA: Confirmatory factor analysis; ESEM: Exploratory structural equation modeling; S-Factors: Specific factors from the bifactor model; Nu: Global need nurturing behaviors; Su: Need supportive behaviors; Th: Need thwarting behaviors; A: Autonomy; C: Competence; R: Relatedness; $\lambda$ : Factor loading; $\delta$ : Item uniqueness; $\omega$ : Model-based omega composite reliability; Target factor loadings are in bold; $* p<.05 ; * * p<.01$. 
Table 5

Measurement Invariance for the Final Retained Model on the Interpersonal Behaviours Questionnaire

\begin{tabular}{|c|c|c|c|c|c|c|c|c|c|c|}
\hline Model & $\chi^{2}(\mathrm{df})$ & CFI & TLI & RMSEA & $90 \% \mathrm{CI}$ & Comparison & $\Delta \chi^{2}(\mathrm{df})$ & $\Delta \mathrm{CFI}$ & $\Delta \mathrm{TLI}$ & $\begin{array}{l}\triangle \mathrm{RMSE} \\
\mathrm{A}\end{array}$ \\
\hline Sample invariance & & & & & & & & & & \\
\hline S1. Configural invariance & $394.268(258)^{*}$ & & .982 & .026 & $.021-.032$ & $\overline{\mathrm{C}_{1}}$ & $\overline{14}$ & & & \\
\hline S2. Weak invariance & $35.300(377)^{*}$ & & & & & S1 & $5(119)$ & 002 & +.004 & -.002 \\
\hline S3. Strong invariance & $568.517(394) *$ & .989 & .985 & .024 & $.020-.028$ & S2 & $8.635(17)^{*}$ & -.001 & -.001 & .000 \\
\hline S4. Strict invariance & $721.312(418)^{*}$ & 982 & .976 & .031 & $.027-.035$ & S3 & $113.308(24) *$ & -.007 & -.009 & +.007 \\
\hline S5. Latent var.-covar. invariance & $760.470(446)^{*}$ & 981 & .976 & .031 & $.027-.034$ & S4 & $43.592(28)$ & -.001 & .000 & .000 \\
\hline S6. Latent means invariance & $780.035(453)^{*}$ & .980 & .976 & .031 & $.027-.035$ & S5 & $3(7)^{*}$ & -.001 & .000 & .000 \\
\hline $\begin{array}{l}\text { Gender invariance } \\
\text { G1. Configural inva }\end{array}$ & & & & & & & & & & \\
\hline G2. Weak invariance & $(377)^{*}$ & .990 & .986 & .024 & 28 & G1 & $125.169(119)$ & +.001 & +.009 & .006 \\
\hline G3. Strong invariance & $558.178(394)^{*}$ & 990 & .986 & .023 & $.019-.028$ & $\mathrm{G} 2$ & 19 & .000 & .000 & .001 \\
\hline G4. Strict invariance & $616.321(418)^{*}$ & .988 & .984 & .025 & $.021-.029$ & G3 & $52.491(24) *$ & -.002 & -.002 & +.002 \\
\hline G5. Latent var.-covar. invariance & $624.523(446)^{*}$ & .989 & .987 & .023 & $.019-.027$ & G4 & $25.924(28)$ & +.001 & +.003 & -.002 \\
\hline G6. Latent means invariance & $650.507(453)^{*}$ & .988 & .985 & .024 & $.020-.028$ & G5 & $33.163(7)^{*}$ & -.001 & -.002 & +.001 \\
\hline \multicolumn{11}{|l|}{ Criterion validity across samples } \\
\hline CS1. Freely estimated & $1206.719(759)^{*}$ & .979 & .971 & .028 & $.025-.031$ & - & - & & & \\
\hline CS2. Invariant regression slo & $(822)^{*}$ & 977 & .971 & .028 & & CS1 & 110 & 02 & مO & .000 \\
\hline CS3. Invariant regres & $1344.997(831)^{*}$ & .976 & .970 & .029 & $.026-.031$ & $\mathrm{Cs}$ & $32.529(9)^{*}$ & -.001 & -.001 & +.001 \\
\hline CS4. Invariant regression residuals & $1476.195(840)^{*}$ & .971 & .963 & .032 & $.029-.034$ & $\mathrm{CS}$ & $157.610(9)^{*}$ & -.005 & -.007 & +.003 \\
\hline \multicolumn{11}{|l|}{ Criterion validity across genders } \\
\hline CG1. Freely estimated & $1122.567(759)^{*}$ & .984 & .977 & .025 & $.022-.028$ & & - & - & - & \\
\hline CG2. Invariant regression slopes & $1213.899(822)^{*}$ & 982 & .977 & .025 & $.022-.028$ & CG1 & $91.504(63)$ & -.002 & .000 & .000 \\
\hline CG3. Invariant regression intercepts & $1424.042(831)^{*}$ & .973 & .966 & .031 & $.028-.033$ & CG2 & $235.535(9) *$ & -.009 & -.011 & +.006 \\
\hline CG3p. Invariant intercepts (partial) & $1343.905(830)^{*}$ & .977 & .970 & .029 & $.026-.031$ & $\mathrm{CG} 2$ & $157.290(8) *$ & -.005 & -.007 & +.004 \\
\hline CG4. Invariant regression residuals & $1373.750(839)^{*}$ & .976 & .969 & .029 & $.026-.032$ & CG3p & $30.524(9)^{*}$ & -.001 & -.001 & .000 \\
\hline
\end{tabular}

Note. $\chi^{2}$ : Robust chi-square test of exact fit; df: Degrees of freedom; CFI: Comparative fit index; TLI: Tucker-Lewis index; RMSEA: Root mean square error of approximation; 90\% CI: 90\% confidence interval of the RMSEA; $\Delta \chi^{2}=$ Robust (Satorra-Bentler) chi-square difference test (calculated from loglikelihood for greater precision); $\Delta$ : Change in model fit in relation to the comparison model; $* p<.01$. 
Table 6

Criterion-Related Validity of the Interpersonal Behaviours Questionnaire

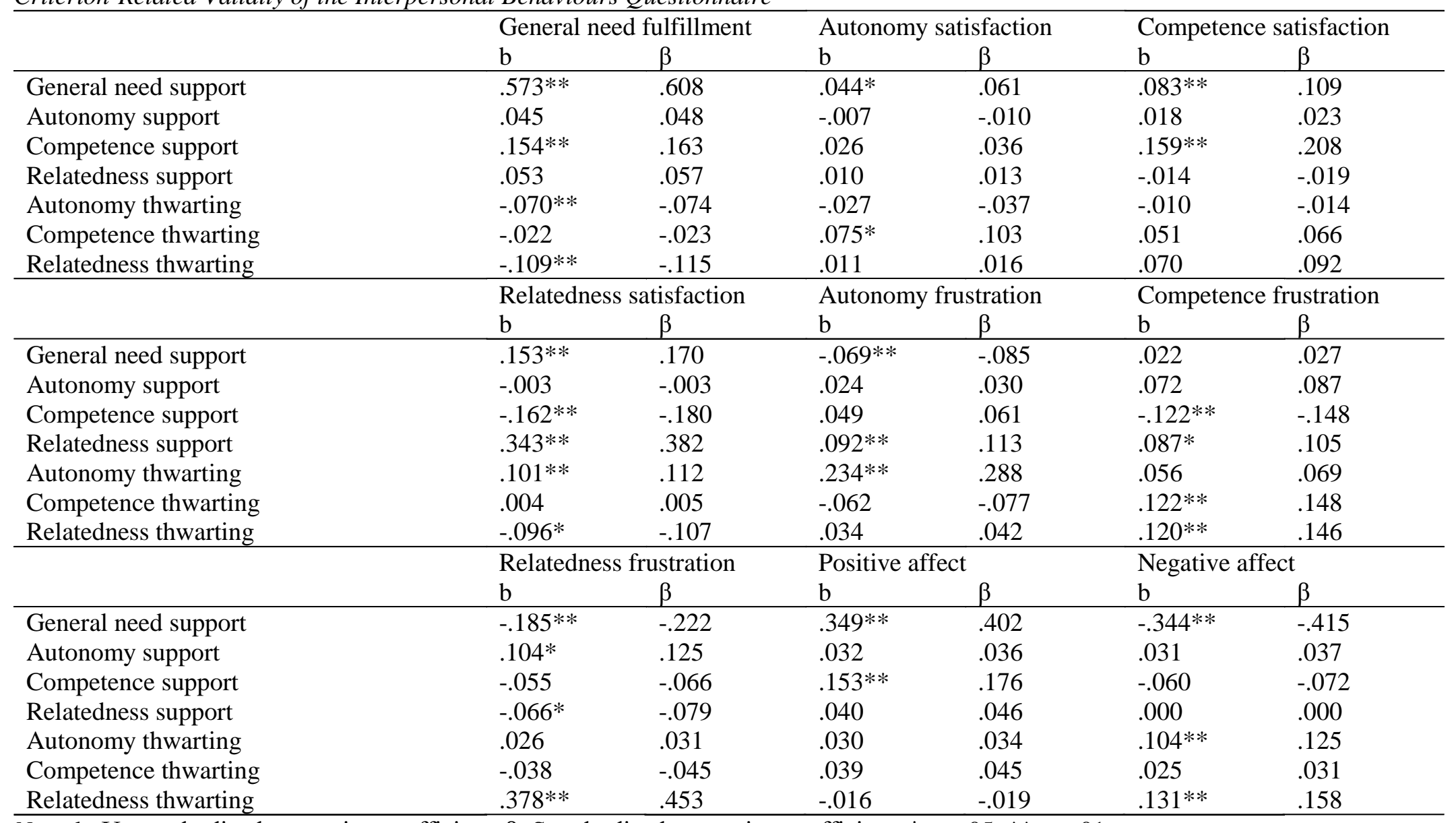

Note. b: Unstandardized regression coefficient; $\beta$ : Standardized regression coefficient; ${ }^{*} p<.05 ; * * p<.01$. 
Supplements for Need Supportive and Need Thwarting Interpersonal Behaviors S1

Online Supplemental Materials for:

Refining the Assessment of Need Supportive and Need Thwarting Interpersonal Behaviors Using the Bifactor Exploratory Structural Equation Modeling Framework 
Items from the Interpersonal Behaviours Questionnaire

Hungarian Version

English Version (Rocchi et al., 2017a)

Személyközi Viselkedések Kérdöív
Title

Instructions
Jelöld be, milyen mértékben értesz egyet azzal, hogy ezek a viselkedések jellemzőek a körülötted élőkre! Sokan részei lehetnek az életednek, de most azokra gondolj, ak a leginkább hatással lehetnek rád!

Minden tétel az alábbi módon kezdődik:
Interpersonal Behaviours Questionnaire

Indicate the degree to which you agree or disagree with the statements below which describe the behaviors of the people living around you. Many people can be part of your life, but for now, focus only on those people who are the most likely to have an influence on you! Each sentence starts with the following stem:

The people in my life..

Az emberek az életemben..

\begin{tabular}{|c|c|c|}
\hline \multirow{8}{*}{ Rating Scale } & & \\
\hline & 1 - egyáltalán nem értek egyet & 1 - do not agree at all \\
\hline & $2-$ & $2-$ \\
\hline & $3-$ & $3-$ \\
\hline & $4-$ & $4-$ \\
\hline & $5-$ & $5-$ \\
\hline & $6-$ & $6-$ \\
\hline & 7 - teljes mértékben egyetértek & 7 - completely agree \\
\hline Item 1 (Autonomy Support) & \multicolumn{2}{|c|}{...megadják a szabadságot, hogy saját döntéseket hozzak. ...Give me the freedom to make my own choices. } \\
\hline Item 2 (Autonomy Thwarting) & \multicolumn{2}{|c|}{$\begin{array}{l}\text {..nnyomást gyakorolnak rám, hogy úgy csináljam a } \\
\text { dolgaimat, ahogy szerintük kellene. }\end{array}$} \\
\hline Item 3 (Relatedness Support) & ...érdeklődnek az iránt, amit csinálok. & ...Are interested in what I do. \\
\hline Item 4 (Relatedness Thwarting) & ...nem törödnek velem, amikor magam alatt vagyok. & ..Do not comfort me when I am feeling low. \\
\hline Item 5 (Competence Support) & ...bátorítanak, hogy fejlesszem a képességeimet. & ...Encourage me to improve my skills. \\
\hline Item 6 (Competence Thwarting) & \multicolumn{2}{|c|}{$\begin{array}{l}\text {. célozgatnak arra, hogy valószínúleg nem fogom elérni a ...Point out that I will likely fail. } \\
\text { céljaimat. }\end{array}$} \\
\hline Item 7 (Autonomy Support) & ...támogatják a döntéseimet. & ...Support my decisions. \\
\hline Item 8 (Autonomy Thwarting) & ...rám eröltetik a véleményüket. & ...Impose their opinions on me. \\
\hline Item 9 (Relatedness Support) & ...időt szentelnek arra, hogy megismerjenek. & ...Take the time to get to know me. \\
\hline Item 10 (Relatedness Thwarting) & ...távolságtartóak velem. & ...Are distant when we spend time together \\
\hline Item 11 (Competence Support) & ...értékes visszajelzést adnak. & ...Provide valuable feedback. \\
\hline Item 12 (Competence Thwarting) & ...azt sugallják, hogy nem értek semmihez. & .. Send me the message that I am incompetent. \\
\hline Item 13 (Autonomy Support) & ...támogatják azt, amikor elhatározom magam valamiben. & ...Support the choices that I make for myself. \\
\hline Item 14 (Autonomy Thwarting) & $\begin{array}{l}\text {...arra kényszerítenek, hogy úgy viselkedjek, ahogy ők } \\
\text { akarják. }\end{array}$ & ..Pressure me to adopt certain behaviours. \\
\hline
\end{tabular}




\begin{tabular}{|c|c|c|}
\hline & Hungarian Version & English Version (Rocchi et al., 2017a) \\
\hline Item 15 (Relatedness Support) & ....tényleg élvezik a velem töltött idöt. & Honestly enjoy spending time with me. \\
\hline Item 16 (Relatedness Thwarting) & ...nem keresik a társaságomat. & Do not connect with me. \\
\hline Item 17 (Competence Support) & ...elismerik, hogy képes vagyok elérni a céljaimat. & Acknowledge my ability to achieve my goals. \\
\hline Item 18 (Competence Thwarting) & ...kételkednek abban, hogy képes vagyok fejlödni. & Doubt my capacity to improve. \\
\hline Item 19 (Autonomy Support) & $\begin{array}{l}\text {..bátorítanak abban, hogy saját magam hozzam meg a } \\
\text { döntéseim. }\end{array}$ & Encourage me to make my own decisions. \\
\hline Item 20 (Autonomy Thwarting) & . korlátozzák a választási lehetőségeimet. & Limit my choices. \\
\hline Item 21 (Relatedness Support) & ...igazán közel állnak hozzám. & Relate to me. \\
\hline Item 22 (Relatedness Thwarting) & ...nem foglalkoznak azzal, hogy mi van velem. & ...Do not care about me. \\
\hline Item 23 (Competence Support) & $\begin{array}{l}\text {...úgy gondolják, hogy véghez tudom vinni, amit } \\
\text { elkezdek. }\end{array}$ & ...Tell me that I can accomplish things. \\
\hline Item 24 (Competence Thwarting) & $\begin{array}{l}\text {...megkérdőjelezik, hogy képes vagyok megküzdeni a } \\
\text { kihívásaimmal. }\end{array}$ & Question my ability to overcome challenges. \\
\hline
\end{tabular}


Table S1

Description of the contrasted CFA- and ESEM-based models

\begin{tabular}{|c|c|c|}
\hline \# & Structure & Factors \\
\hline Model 1 & One-factor CFA & - Global need nurturing behaviors \\
\hline Model 2 & Two-factor CFA & - Global need supportive and thwarting behaviors \\
\hline Model 3 & Two-factor ESEM & - Global need supportive and thwarting behaviors \\
\hline Model 4 & Three-factor CFA & - Global nurturing of the needs for autonomy, relatedness, and competence \\
\hline Model 5 & Three-factor ESEM & - Global nurturing of the needs for autonomy, relatedness, and competence \\
\hline Model 6 & Six-factor CFA & $\begin{array}{l}\text { - Autonomy supportive and thwarting behaviors, competence supportive and } \\
\text { thwarting behaviors, and relatedness supportive and thwarting behaviors }\end{array}$ \\
\hline Model 7 & Six-factor ESEM & $\begin{array}{l}\text { - Autonomy supportive and thwarting behaviors, competence supportive and } \\
\text { thwarting behaviors, and relatedness supportive and thwarting behaviors }\end{array}$ \\
\hline Model 8 & Bifactor-CFA with $1 \mathrm{G}$ - and $2 \mathrm{~S}$-factors & - Global need nurturing behaviors; need supportive and thwarting behaviors \\
\hline Model 9 & Bifactor-ESEM with $1 \mathrm{G}$ - and $2 \mathrm{~S}$-factors & - Global need nurturing behaviors; need supportive and thwarting behaviors \\
\hline Model 10 & Bifactor-CFA with $1 \mathrm{G}$ - and $3 \mathrm{~S}$-factors & - Global need nurturing behaviors; autonomy, competence, and relatedness \\
\hline Model 11 & Bifactor-ESEM with $1 \mathrm{G}$ - and $3 \mathrm{~S}$-factors & - Global need nurturing behaviors; autonomy, competence, and relatedness \\
\hline Model 12 & Bifactor-CFA with 2 G- and 3 S-factors & $\begin{array}{l}\text { - Need supportive and thwarting behaviors; autonomy, competence, and } \\
\text { relatedness }\end{array}$ \\
\hline Model 13 & Bifactor-ESEM with 2 G- and 3 S-factors & $\begin{array}{l}\text { - Need supportive and thwarting behaviors; autonomy, competence, and } \\
\text { relatedness }\end{array}$ \\
\hline Model 14 & Bifactor-CFA with $1 \mathrm{G}$ - and $6 \mathrm{~S}$-factors & $\begin{array}{l}\text { - Global need nurturing behaviors; autonomy supportive and thwarting } \\
\text { behaviors, competence supportive and thwarting behaviors, and relatedness } \\
\text { supportive and thwarting behaviors }\end{array}$ \\
\hline Model 15 & Bifactor-ESEM with $1 \mathrm{G}$ - and $6 \mathrm{~S}$-factors & $\begin{array}{l}\text { - Global need nurturing behaviors; autonomy supportive and thwarting } \\
\text { behaviors, competence supportive and thwarting behaviors, and relatedness } \\
\text { supportive and thwarting behaviors }\end{array}$ \\
\hline Model 16 & Bifactor-CFA with 2 G- and $6 \mathrm{~S}$-factors & $\begin{array}{l}\text { - Need supportive and thwarting behaviors; autonomy supportive and } \\
\text { thwarting behaviors, competence supportive and thwarting behaviors, and } \\
\text { relatedness supportive and thwarting behaviors }\end{array}$ \\
\hline Model 17 & Bifactor-ESEM with 2 G- and 6 S-factors & $\begin{array}{l}\text { - Need supportive and thwarting behaviors; autonomy supportive and } \\
\text { thwarting behaviors, competence supportive and thwarting behaviors, and } \\
\text { relatedness supportive and thwarting behaviors }\end{array}$ \\
\hline
\end{tabular}

Note. CFA: confirmatory factor analysis; ESEM: exploratory structural equation modeling; G-factor: Global factor estimated as part of a bifactor model; Sfactor: Specific factor estimated as part of a bifactor model. 
Table S2

Standardized Parameter Estimates from the Six-Factor CFA and ESEM Solutions in Study $2(N=742)$ : Interpersonal Behaviours Questionnaire

\begin{tabular}{|c|c|c|c|c|c|c|c|c|c|}
\hline & \multicolumn{2}{|c|}{ CFA } & \multicolumn{7}{|c|}{ ESEM } \\
\hline & Factor $(\lambda)$ & $\delta$ & $\mathrm{A}-\mathrm{Su}(\lambda)$ & $\mathrm{C}-\mathrm{Su}(\lambda)$ & $\mathrm{R}-\mathrm{Su}(\lambda)$ & $\mathrm{A}-\mathrm{Th}(\lambda)$ & C-Th $(\lambda)$ & R-Th $(\lambda)$ & $\delta$ \\
\hline Autonomy-support (A-Su) & & & & & & & & & \\
\hline Item 1 & $.685 * *$ & .531 & $.389 * *$ & .020 & .124 & $-.408 * *$ & .009 & .088 & .463 \\
\hline Item 7 & $836 * *$ & 300 & $.763 * *$ & .114 & -100 & -016 & -004 & -.122 & 255 \\
\hline Item 13 & $.858 * *$ & .263 & $.711 * *$ & .130 & -.009 & .004 & -.049 & -.082 & .245 \\
\hline Item 19 & $.828 * *$ & .315 & $.587 * *$ & .063 & $.187 *$ & $-.165 *$ & .075 & -.037 & .320 \\
\hline & .879 & & .824 & & & & & & \\
\hline Competence-support (C-Su) & & & & & & & & & \\
\hline Item 3 & $.725 * *$ & .474 & $.375^{* *}$ & $.394 * *$ & .098 & .031 & -.054 & .025 & .420 \\
\hline Item 9 & $.683 * *$ & .534 & -.049 & $.609 *$ & .136 & $-.118^{*}$ & -.016 & -.115 & .396 \\
\hline Item 15 & $.877 * *$ & .231 & $.249 * *$ & $.337 *$ & $.236 * *$ & .018 & $-.339 * *$ & .079 & .233 \\
\hline Item 21 & $.868 * *$ & .247 & $.289 *$ & .181 & $.333 * *$ & .062 & $-.419 * *$ & .120 & .207 \\
\hline & .870 & & & .648 & & & & & \\
\hline Relatedness-support (R-Su) & & & & & & & & & \\
\hline Item 5 & $.734 * *$ & .461 & .111 & $.471 * *$ & .171 & -.050 & -.010 & -.143 & .400 \\
\hline Item 11 & $.822 * *$ & .325 & -.009 & $.361 * *$ & $.373 *$ & $-.134 * *$ & .058 & $-.261 * *$ & .300 \\
\hline Item 17 & $.826 * *$ & .318 & .118 & .101 & $.510 * *$ & .005 & -.071 & $-.229 *$ & .288 \\
\hline Item 23 & $.821 * *$ & .326 & $.179 *$ & .065 & $.363 * *$ & -.036 & .055 & $-.412 * *$ & .315 \\
\hline$\omega$ & .878 & & & & .606 & & & & \\
\hline Autonomy-thwarting (A-Th) & & & & & & & & & \\
\hline Item 2 & $.790 * *$ & .376 & -.063 & -.055 & .035 & $.715 * *$ & .058 & -.014 & .372 \\
\hline Item 8 & $.835 * *$ & .303 & -.035 & -.051 & -.004 & $.801 * *$ & .035 & -.044 & .287 \\
\hline Item 14 & $.837 * *$ & .299 & .002 & .034 & -.034 & $.748 * *$ & $.131 * *$ & .029 & .293 \\
\hline Item 20 & $.836 * *$ & .302 & $-.189 *$ & .102 & .009 & $.669 * *$ & $.084 *$ & .080 & .301 \\
\hline & .895 & & & & & .873 & & & \\
\hline Competence-thwarting (C-Th) & & & & & & & & & \\
\hline Item 4 & $.793 * *$ & .372 & -.055 & -.098 & $.191 * *$ & .015 & $.781 * *$ & .097 & .307 \\
\hline Item 10 & $.787 * *$ & .381 & -.013 & .021 & .049 & $.162 *$ & $.605 * *$ & $.191 * *$ & .378 \\
\hline Item 16 & $.807 * *$ & .348 & .119 & -.119 & -.092 & .095 & $.656 * *$ & .108 & .347 \\
\hline Item 22 & $.828 * *$ & .315 & -.009 & -.080 & -.075 & $.173 * *$ & $.622 * *$ & .005 & .321 \\
\hline & .880 & & & & & & .840 & & \\
\hline Relatedness-thwarting (R-Th) & & & & & & & & & \\
\hline Item 6 & $.744 * *$ & .446 & -.108 & -.121 & .164 & .027 & $.162 *$ & $.657 * *$ & .354 \\
\hline Item 12 & $.816 * *$ & .334 & .018 & .041 & $-.283 *$ & .035 & $.141 * *$ & $.556 * *$ & .331 \\
\hline Item 18 & $.794 * *$ & .370 & -.039 & .092 & $-.310 * *$ & -.011 & $.135 *$ & $.534 * *$ & .359 \\
\hline Item 24 & $.865 * *$ & .252 & -.097 & .019 & $-.176^{*}$ & .080 & .036 & $.655 * *$ & .241 \\
\hline$\omega$ & .881 & & & & & & & .818 & \\
\hline
\end{tabular}

Note. CFA: Confirmatory factor analysis; ESEM: Exploratory structural equation modeling; Su: Need supportive behaviors; Th: Need thwarting behaviors; A: Autonomy; C: Competence; R: Relatedness; $\lambda$ : Factor loading; $\delta$ : Item uniqueness; $\omega$ : Model-based omega composite reliability; Target factor loadings are in bold; $* p<.05 ; * * p<.01$ 
Table S3

Standardized Parameter Estimates from the Bifactor-ESEM Solution Including Six S-Factors and One G-Factor in Study $2(N=742):$ Interpersonal Behaviours Questionnaire

\begin{tabular}{|c|c|c|c|c|c|c|c|c|}
\hline & $\mathrm{Nu}(\lambda)$ & $\mathrm{A}-\mathrm{Su}(\lambda)$ & $\mathrm{C}-\mathrm{Su}(\lambda)$ & $\mathrm{R}-\mathrm{Su}(\lambda)$ & A-Th $(\lambda)$ & C-Th $(\lambda)$ & R-Th $(\lambda)$ & $\delta$ \\
\hline \multicolumn{9}{|l|}{ Autonomy-support (A-Su) } \\
\hline Item 1 & $.626 * *$ & .178 & -.069 & .046 & $-.304 * *$ & .016 & 109 & .464 \\
\hline Item 7 & $.757 * *$ & $.389 * *$ & .051 & -.077 & -.028 & .025 & .061 & .262 \\
\hline Item 13 & $.782 * *$ & $.395 * *$ & .043 & .019 & .003 & -.006 & .060 & .227 \\
\hline Item 19 & $.764 * *$ & $.259 * *$ & -.071 & .015 & $-.088 *$ & $.109 * *$ & .044 & .322 \\
\hline$\omega$ & & .539 & & & & & & \\
\hline \multicolumn{9}{|l|}{ Competence-support (C-Su) } \\
\hline Item 3 & $.701 * *$ & $.213 * *$ & .167 & .092 & $.106^{* *} *$ & .015 & $.119^{*}$ & .401 \\
\hline Item 9 & $.717 * *$ & -.065 & .267 & -.055 & $.076^{*}$ & .082 & .021 & .394 \\
\hline Item 15 & $.849 * *$ & .069 & -.034 & .004 & $.094 * *$ & $-.115 * *$ & $.137 * *$ & .233 \\
\hline Item 21 & $.848 * *$ & .042 & -.228 & .007 & $.115^{* *}$ & $-.145 * *$ & $.158 * *$ & .168 \\
\hline \multicolumn{9}{|l|}{$\begin{array}{l}\omega \\
\text { Relatedness-support (C-Su) }\end{array}$} \\
\hline Item 5 & $.735 * *$ & .040 & $.221 * *$ & .061 & $.097 *$ & .067 & -.023 & .392 \\
\hline Item 11 & $.791 * *$ & -.088 & .096 & .056 & $.066 *$ & $.149 * *$ & $-.158 * *$ & .302 \\
\hline Item 17 & $.780 * *$ & -.041 & $-.104 *$ & .177 & $.122 * *$ & .070 & $-.187 * *$ & .294 \\
\hline Item 23 & $.758 * *$ & -.020 & -.058 & .024 & $.078 *$ & .146 & $-.280 * *$ & .315 \\
\hline & & & & .071 & & & & \\
\hline \multicolumn{9}{|l|}{ Autonomy-thwarting (A-Th) } \\
\hline Item 2 & $-.546 * *$ & -.063 & -.068 & -.038 & $.564 * *$ & $.099 * *$ & -.036 & .363 \\
\hline Item 8 & $-.568 * *$ & -.036 & -.033 & -.003 & $.616 * *$ & $.075^{*}$ & -.050 & .288 \\
\hline Item 14 & $-.586 * *$ & .020 & .051 & .038 & $.589 * *$ & $.118 *$ & .013 & .291 \\
\hline Item 20 & $-.613 * *$ & -.074 & .068 & .060 & $.551 * *$ & $.087 *$ & .026 & .299 \\
\hline \multirow{2}{*}{\multicolumn{6}{|c|}{ Competence-thwarting (R-Th) }} & & & \\
\hline Item 4 & $-.633 * *$ & -.041 & -.016 & 062 & $097 * *$ & & & 304 \\
\hline Item 10 & $-.643 * *$ & .024 & .066 & .072 & $.186 * *$ & $.393 * *$ & $.097 *$ & 378 \\
\hline Item 16 & $-.680 * *$ & .078 & .011 & -.100 & $.085 * *$ & .425** & .065 & .329 \\
\hline Item 22 & $-.708 * *$ & .045 & .105 & .025 & $.156 * *$ & $.373 * *$ & -.040 & .320 \\
\hline & & & & & & .690 & & \\
\hline \multicolumn{9}{|l|}{ Relatedness-thwarting (C-Th) } \\
\hline Item 6 & $-.667 * *$ & .000 & -.164 & .206 & .010 & .076 & $.359 * *$ & .351 \\
\hline Item 12 & $-.678 * *$ & .066 & .004 & -.199 & -.024 & .056 & $.446 * *$ & .294 \\
\hline Item 18 & $-.658 * *$ & .040 & .061 & $-.208 * *$ & -.053 & .045 & $.439 * *$ & .321 \\
\hline Item 24 & $-.751 * *$ & .069 & .033 & .123 & .002 & -.065 & $.456 * *$ & .202 \\
\hline$\Omega$ & .974 & & & & & & .712 & \\
\hline
\end{tabular}

Note. CFA: Confirmatory factor analysis; ESEM: Exploratory structural equation modeling; S-Factors: Specific factors from the bifactor model; Nu: Global need nurturing behaviors; Su: Need supportive behaviors; Th: Need thwarting behaviors; A: Autonomy; C: Competence; R: Relatedness; $\lambda$ : Factor loading; $\delta$ : Item uniqueness; $\omega$ : Model-based omega composite reliability; Target factor loadings are in bold; * $p<.05 ; * * p<.01$. 
Table S4

Goodness-of-Fit Statistics for the Models Estimated on the Basic Psychological Need Satisfaction and Frustration Scale In Study 1 (N = 772)

\begin{tabular}{|c|c|c|c|c|c|c|}
\hline Model & $\chi^{2}$ & df & CFI & TLI & RMSEA & RMSEA 90\% CI \\
\hline \multicolumn{7}{|l|}{ Study 1} \\
\hline Model 1. One-factor CFA (Fu) & $2135.585^{*}$ & 252 & 687 & 657 & .098 & $.095-.102$ \\
\hline Model 2. Two-factor CFA (S, Fr) & $1881.457 *$ & 251 & .729 & .702 & .092 & $.088-.096$ \\
\hline Model 3. Two-factor ESEM (S, Fr) & $1282.759 *$ & 229 & .825 & .789 & .077 & $.073-.081$ \\
\hline Model 4. Three-factor CFA (A, C, R) & $1117.627 *$ & 249 & .856 & .840 & .067 & $.063-.071$ \\
\hline Model 5. Three-factor ESEM (A, C, R) & $988.798 *$ & 207 & .870 & .827 & .070 & $.066-.074$ \\
\hline Model 6. Six-factor CFA (A-S, A-Fr, C-S, C-Fr, R-S, R-Fr) & $547.791 *$ & 237 & 948 & .940 & .041 & $.037-.046$ \\
\hline Model 7. Six-factor ESEM (A-S, A-Fr, C-S, C-Fr, R-S, R-Fr) & $271.235^{*}$ & 147 & .979 & .961 & .033 & $.027-.039$ \\
\hline Model 8. B-CFA: Two S-factors (S, Fr) and one G-factor (Fu) & $1231.423 *$ & 228 & .833 & .798 & .076 & $.071-.080$ \\
\hline Model 9. B-ESEM: Two S-factors (S, Fr) and one G-factor (Fu) & $988.798 *$ & 207 & .870 & .827 & .070 & $.066-.074$ \\
\hline Model 10. B-CFA: Three S-factors (A, C, R) and one G-factor (Fu) & $884.484 *$ & 228 & .891 & .868 & .061 & $.057-.065$ \\
\hline Model 11. B-ESEM: Three S-factors (A, C, R) and one G-factor (Fu) & $444.995^{*}$ & 186 & .957 & .936 & .042 & $.037-.048$ \\
\hline Model 12. B-CFA: Three S-factors (A, C, R) and two G-factors (S, Fr) & $456.760 *$ & 227 & .962 & .954 & .036 & $.031-.041$ \\
\hline Model 13. B-ESEM: Three S-factors (A, C, R) and two G-factors (S, Fr) & $394.045 *$ & 182 & .965 & 947 & .039 & $.034-.044$ \\
\hline Model 14. B-CFA: Six S-factors (A-S, A-Fr, C-S, C-Fr, R-S, R-Fr) and one G-factor (Fu) & $755.023^{*}$ & 228 & 912 & .894 & .055 & $.050-.059$ \\
\hline Model 15. B-ESEM: Six S-factors (A-S, A-Fr, C-S, C-Fr, R-S, R-Fr) and one G-factor (Fu) & $194.693 *$ & 129 & .989 & 977 & .026 & $.018-.033$ \\
\hline Model 16. B-CFA: Six S-factors (A-S, A-Fr, C-S, C-Fr, R-S, R-Fr) and two G-factor (S, Fr) & $738.264 *$ & 227 & 915 & .897 & .054 & $.050-.058$ \\
\hline Model 17. B-ESEM: Six S-factors (A-S, A-Fr, C-S, C-Fr, R-S, R-Fr) and two G-factor (S, Fr) & $179.585^{*}$ & 122 & .990 & .978 & .025 & $.017-.032$ \\
\hline
\end{tabular}

Note. CFA: Confirmatory factor analysis; ESEM: Exploratory structural equation modeling; B: Bifactor model; Fu: Global need fulfillment; S: Need satisfaction;

Fr: Need frustration; A: Need for autonomy; C: Need for competence; R: Need for relatedness; G-factor: Global factor estimated as part of a bifactor model; Sfactor: Specific factor estimated as part of a bifactor model; $\chi^{2}$ : Robust chi-square test of exact fit; df: Degrees of freedom; CFI: Comparative fit index; TLI:

Tucker-Lewis index; RMSEA: Root mean square error of approximation; 90\% CI: 90\% confidence interval of the RMSEA; * $p<.01$. 
Table S5

Standardized Parameter Estimates from the Six-Factor CFA and ESEM Solutions in Study 1 (N = 772): Basic Psychological Need Satisfaction and Frustration Scale

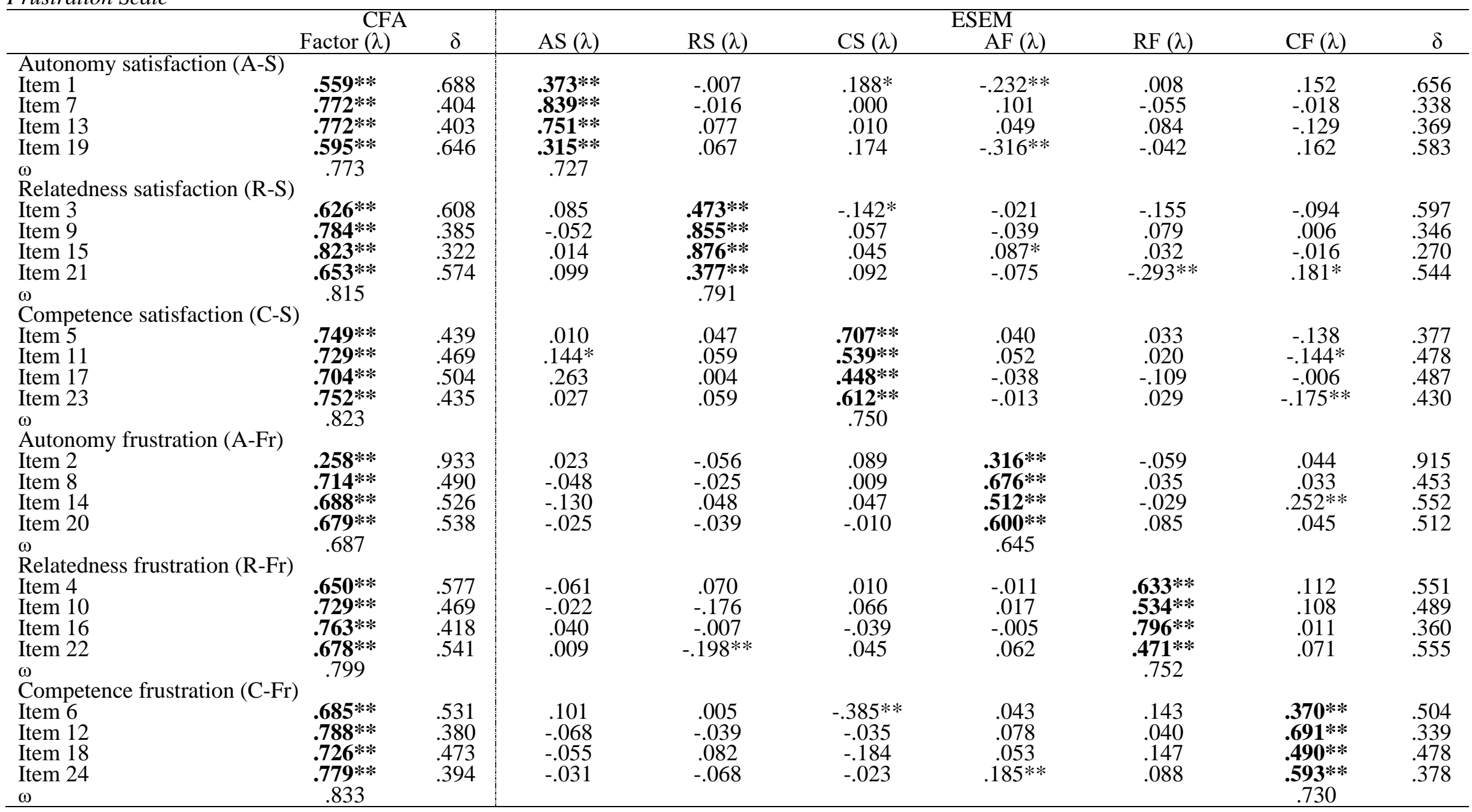

Note. CFA: Confirmatory factor analysis; ESEM: Exploratory structural equation modeling; S: Need satisfaction; Fr: Need frustration; A: Need for autonomy; $\mathrm{C}$ : Need for competence; R: Need for relatedness; $\lambda$ : Factor loading; $\delta$ : Item uniqueness; $\omega$ : Model-based omega composite reliability; Target factor loadings are in bold; $* p<.05 ; * * p<.01$. 
Table S6

Latent Factor Correlations from the Six-Factor CFA (Under the Diagonal) and ESEM (Over the Diagonal) Solutions in Study 1 (N = 772): Basic Psychological Need Satisfaction and Frustration Scale

\begin{tabular}{lcccccc}
\hline & $\mathrm{A}-\mathrm{S}$ & $\mathrm{R}-\mathrm{S}$ & $\mathrm{C}-\mathrm{S}$ & $\mathrm{A}-\mathrm{Fr}$ & $\mathrm{R}-\mathrm{Fr}$ & $\mathrm{C}-\mathrm{Fr}$ \\
\hline Autonomy satisfaction (A-S) & - & .435 & .602 & -.527 & -.410 & -.423 \\
Relatedness satisfaction (R-S) & .523 & - & .260 & -.310 & -.663 & -.249 \\
Competence satisfaction (C-S) & .768 & .413 & - & -.327 & -.311 & -.574 \\
Autonomy frustration (A-Fr) & -.672 & -.407 & -.502 & - & .489 & .334 \\
Relatedness frustration (R-Fr) & -.489 & -.751 & -.462 & .613 & - & .485 \\
Competence frustration (C-Fr) & -.628 & -.423 & -.815 & .656 & .679 & - \\
\hline
\end{tabular}

Note. CFA: Confirmatory factor analysis; ESEM: Exploratory structural equation modeling; Values above the diagonal are from the ESEM model; Values below the diagonal are from the CFA model; All correlations are statistically significant $(p \leq .01)$. These correlations involve latent factors for which the scale was set using the referent indicator approach, and thus having a mean of 0 and a SD of 1. 
Table S7

Standardized Parameter Estimates from the Bifactor-ESEM Solution Including Six S-Factors and One G-Factor in Study 1 (N = 772): Basic Psychological Need Satisfaction and Frustration Scale

\begin{tabular}{|c|c|c|c|c|c|c|c|c|}
\hline & $\mathrm{Fu}(\lambda)$ & $\mathrm{A}-\mathrm{S}(\lambda)$ & $\mathrm{R}-\mathrm{S}(\lambda)$ & $\mathrm{C}-\mathrm{S}(\lambda)$ & $\mathrm{A}-\operatorname{Fr}(\lambda)$ & $\operatorname{R-Fr}(\lambda)$ & C-Fr $(\lambda)$ & $\delta$ \\
\hline Autonomy satisfaction (A-S) & & & & & & & & \\
\hline Item 1 & $.493 * *$ & 145 & -.041 & .103 & $-.181 *$ & .085 & .184 & .650 \\
\hline Item 7 & $.704 *$ & .307 & -.032 & .001 & .075 & .133 & .124 & .370 \\
\hline Item 13 & $.698 *$ & .390 & -.001 & .025 & .034 & .177 & .054 & .325 \\
\hline Item 19 & $.704 * *$ & -.374 & -.047 & -.114 & -.029 & .217 & .257 & .234 \\
\hline & & .483 & & & & & & \\
\hline \multicolumn{9}{|l|}{ Relatedness satisfaction (R-S) } \\
\hline Item 3 & $.430 * *$ & .002 & $.402 * *$ & $-.138 * *$ & .004 & $-.191 * *$ & -.023 & .597 \\
\hline Item 9 & $.444 * *$ & -.014 & $.672 * *$ & .004 & -.005 & -.101 & .034 & .340 \\
\hline Item 15 & $.469 * *$ & .038 & $.691 * *$ & .012 & $.082 *$ & -.134 & .031 & .276 \\
\hline Item 21 & $.512 * *$ & -.048 & $.351 * *$ & -.047 & -.015 & -.205 & .143 & .547 \\
\hline & & & .718 & & & & & \\
\hline \multicolumn{9}{|l|}{ Competence satisfaction $(\mathrm{C}-\mathrm{S})$} \\
\hline Item 5 & $.544 * *$ & .086 & -.039 & $.589 * *$ & .031 & .048 & $-.141 * *$ & .326 \\
\hline Item 11 & $.600 * *$ & -.019 & -.039 & $.353 * *$ & $.137 *$ & .116 & -.124 & .465 \\
\hline Item 17 & $.667 * *$ & .006 & -.047 & $.241 * *$ & .058 & .058 & -.008 & .488 \\
\hline Item 23 & $.570 * *$ & .051 & -.030 & $.437 * *$ & .030 & .061 & $-.186 * *$ & .442 \\
\hline & & & & .604 & & & & \\
\hline \multicolumn{9}{|l|}{ Autonomy frustration (A-Fr) } \\
\hline Item 2 & $-.142 * *$ & .024 & -.019 & .076 & $.250 * *$ & .002 & .002 & 911 \\
\hline Item 8 & $-.528 * *$ & .035 & .019 & .073 & $.505 * *$ & .056 & -.016 & .456 \\
\hline Item 14 & $-.504 * *$ & -.109 & .093 & .009 & $.453 * *$ & .022 & .129 & .503 \\
\hline Item 20 & $-.540 * *$ & .117 & .004 & .084 & $.399 * *$ & .062 & .010 & .525 \\
\hline & & & & & .519 & & & \\
\hline \multicolumn{9}{|l|}{ Relatedness frustration (R-Fr) } \\
\hline Item 4 & $-.503 * *$ & .026 & -.050 & .043 & .014 & $.426 * *$ & .102 & .550 \\
\hline Item 10 & $-.504 * *$ & -.015 & $-.239 * *$ & .073 & .048 & $.438 * *$ & .086 & .482 \\
\hline Item 16 & $-.539 * *$ & .067 & $-.157 *$ & .051 & .017 & $.555 * *$ & .067 & .365 \\
\hline Item 22 & $-.468 * *$ & -.002 & $-.249 * *$ & .081 & .071 & $.387 * *$ & .075 & .551 \\
\hline \multirow{2}{*}{\multicolumn{9}{|c|}{ Competence frustration (C-Fr) }} \\
\hline & & & & & & & & \\
\hline Item 12 & $-.626 * *$ & -027 & 047 & -080 & .040 & .15063 & $.525 * *$ & .493 \\
\hline Item 18 & $-.583 * *$ & 022 & 117 & 120 & .017 & .005 & $\bullet$ & .348 \\
\hline Item 24 & $647 * *$ & 011 & .111 & -.129 & -.023 & .070 & $.401 \%$ & .463 \\
\hline$\omega$ & $\begin{array}{c}-.042 \\
938\end{array}$ & .011 & .005 & $-.0<1$ & .088 & .095 & $.455 * *$ & .363 \\
\hline
\end{tabular}

Note. CFA: Confirmatory factor analysis; ESEM: Exploratory structural equation modeling; Fu: Global (G-Factor) representing need fulfillment; S-Factors: Specific factors from the bifactor model; S: Need satisfaction; Fr: Need frustration; A: Need for autonomy; C: Need for competence; R: Need for relatedness; $\lambda$ : Factor loading; $\delta$ : Item uniqueness; $\omega$ : Model-based omega composite reliability; Target factor loadings are in bold.; $* p<.05 ; * * p<.01$. 
Table S8

Measurement Invariance for the Final Retained Model on the Basic Psychological Need Satisfaction and Frustration Scale across Studies and Genders

\begin{tabular}{|c|c|c|c|c|c|c|c|c|c|c|}
\hline \multicolumn{11}{|c|}{ Tests of Measurement Invariance } \\
\hline Model & $\chi^{2}(\mathrm{df})$ & CFI & TLI & RMSEA & $90 \% \mathrm{CI}$ & Comparison & $\Delta \chi^{2}(\mathrm{df})$ & $\Delta \mathrm{CFI}$ & $\Delta \mathrm{TLI}$ & $\triangle \mathrm{RMSEA}$ \\
\hline Studies invariance & & & & & & & & & & \\
\hline NS1. Configural invariance & $655.174(258)^{*}$ & .970 & .935 & .045 & $.041-.049$ & - & - & - & - & - \\
\hline NS2. Weak invariance & $597.259(377)^{*}$ & .983 & .975 & .028 & $.024-.032$ & NS1 & $89.789(119)$ & +.013 & +.040 & -.017 \\
\hline NS3. Strong invariance & $661.135(394) *$ & .980 & .971 & .030 & $.026-.034$ & NS2 & $78.101(17)^{*}$ & -.003 & -.004 & +.002 \\
\hline NS4. Strict invariance & $774.310(418) *$ & .973 & .964 & .034 & $.030-.037$ & NS3 & $94.067(24) *$ & -.007 & -.007 & +.004 \\
\hline NS5. Latent var.-covar. invariance & $818.564(446) *$ & .971 & .965 & .033 & $.030-.037$ & NS4 & $46.328(28)^{*}$ & -.002 & +.001 & -.001 \\
\hline NS6. Latent means invariance & $833.585(453) *$ & .971 & .964 & .033 & $.030-.037$ & NS5 & $15.029(7)^{*}$ & .000 & -.001 & .000 \\
\hline Gender invariance & & & & & & & & & & \\
\hline NG1. Configural invariance & $435.131(258)^{*}$ & .986 & .971 & .030 & $.025-.035$ & - & - & - & - & - \\
\hline NG2. Weak invariance & $568.081(377)^{*}$ & .985 & .979 & .026 & $.021-.030$ & NG1 & $141.750(119)$ & -.001 & +.008 & -.004 \\
\hline NG3. Strong invariance & $625.950(394)^{*}$ & .982 & .975 & .028 & $.024-.032$ & NG2 & $68.683(17)^{*}$ & -.003 & -.004 & +.002 \\
\hline NG4. Strict invariance & $695.272(418)^{*}$ & .979 & .972 & .030 & $.026-.033$ & NG3 & $60.210(24)^{*}$ & -.003 & -.003 & +.002 \\
\hline NG5. Latent var.-covar. invariance & $751.342(446)^{*}$ & .977 & .971 & .030 & $.026-.034$ & NG4 & $54.766(28)^{*}$ & -.002 & -.001 & .000 \\
\hline NG6. Latent means invariance & $840.159(453) *$ & .970 & .964 & .034 & $.030-.037$ & NG5 & $87.371(7)^{*}$ & -.007 & -.007 & +.004 \\
\hline
\end{tabular}

Note. $\chi^{2}:$ Robust chi-square test of exact fit; df: Degrees of freedom; CFI: Comparative fit index; TLI: Tucker-Lewis index; RMSEA: Root mean square error of approximation; 90\% CI: 90\% confidence interval of the RMSEA; $\Delta \chi^{2}=$ Robust (Satorra-Bentler) chi-square difference test (calculated from loglikelihood for greater precision); $\Delta$ : Change in model fit in relation to the comparison model; $* p<.01$. 
Table S9

Measurement Invariance for the Two Factor CFA Model of the Positive and Negative Affect Scale

\begin{tabular}{|c|c|c|c|c|c|c|c|c|c|c|}
\hline Model & $\chi^{2}(\mathrm{df})$ & CFI & TLI & RMSEA & $90 \% \mathrm{CI}$ & Comparison & $\Delta \chi^{2}(\mathrm{df})$ & $\Delta \mathrm{CFI}$ & $\Delta \mathrm{TLI}$ & $\triangle \mathrm{RMSEA}$ \\
\hline Studies invariance & & & & & & & & & & \\
\hline PS1. Configural invariance & $276.473(66)^{*}$ & .936 & 913 & .065 & $.057-.073$ & - & - & & 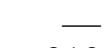 & \\
\hline PS2. Weak invariance & $283.390(74)^{*}$ & .936 & .923 & .061 & $.054-.069$ & PS1 & $8.620(8)$ & .000 & +.010 & -.004 \\
\hline PS3. Strong invariance & $302.907(82)^{*}$ & .933 & .926 & .060 & $.053-.067$ & PS2 & $17.501(8)^{*}$ & -.003 & +.003 & -.001 \\
\hline PS4. Strict invariance & $313.467(92)^{*}$ & .933 & .934 & .056 & $.050-.063$ & PS3 & $13.887(10)$ & .000 & +.008 & -.004 \\
\hline PS5. Latent var.-covar. invariance & $315.360(95)^{*}$ & .933 & .937 & .055 & $.049-.062$ & PS4 & $1.809(3)$ & .000 & +.003 & -.001 \\
\hline PS6. Latent means invariance & $316.724(97)^{*}$ & .933 & .938 & .055 & $.048-.062$ & PS5 & $0.427(2)$ & .000 & +.001 & .000 \\
\hline Gender invariance & & & & & & & & & & \\
\hline PG1. Configural invariance & $286.586(66)^{*}$ & .932 & .908 & .067 & $.059-.075$ & - & - & & - & \\
\hline PG2. Weak invariance & $288.686(74)^{*}$ & .934 & .920 & .062 & $.055-.070$ & PG1 & $3.041(8)$ & +.002 & +.012 & -.005 \\
\hline PG3. Strong invariance & $337.606(82)^{*}$ & .922 & .914 & .064 & $.057-.071$ & PG2 & $53.137(8) *$ & -.012 & -.006 & +.002 \\
\hline PG3p. Partial strong ivariance & $319.297(81)^{*}$ & .927 & 919 & .062 & $.055-.070$ & PG2 & $31.356(7)^{*}$ & -.007 & -.001 & .000 \\
\hline PG4. Strict invariance & $337.760(91)^{*}$ & .924 & .925 & .060 & $.053-.067$ & PG3p & $20.994(10)^{*}$ & -.003 & +.006 & -.002 \\
\hline PG5. Latent var.-covar. i & $343.595(94)^{*}$ & .924 & 927 & .059 & $.053-.066$ & PG4 & $4.911(3)$ & .000 & +.002 & -.001 \\
\hline PG6. Latent means invariance & $345.649(96)^{*}$ & .924 & .928 & .059 & $.052-.065$ & PG5 & $1.421(2)$ & .000 & +.001 & .000 \\
\hline
\end{tabular}

Note. $\chi^{2}$ : Robust chi-square test of exact fit; df: Degrees of freedom; CFI: Comparative fit index; TLI: Tucker-Lewis index; RMSEA: Root mean square error of approximation; $90 \%$ CI: $90 \%$ confidence interval of the RMSEA; $\Delta \chi^{2}=$ Robust (Satorra-Bentler) chi-square difference test (calculated from loglikelihood for greater precision); $\Delta$ : Change in model fit in relation to the comparison model; $* p<.01$ 
Table S10

Parameter Estimates from the Most Invariant Measurement Model (Across Studies) for the Positive and Negative Affect Scale

\begin{tabular}{|c|c|c|c|c|c|c|}
\hline & \multicolumn{2}{|c|}{ Unstandardized $\lambda$} & \multicolumn{2}{|c|}{ Standardized $\lambda$ (males) } & \multicolumn{2}{|c|}{ Standardized $\lambda$ (females) } \\
\hline & Positive affect & Negative affect & Positive affect & Negative affect & Positive affect & Negative affect \\
\hline Item 1 & $.632 * *$ & & $.723 * *$ & & $.708 * *$ & \\
\hline Item 3 & $.538 * *$ & & $.525 * *$ & & $.510 * *$ & \\
\hline Item 5 & $.615^{* *}$ & & $.622 * *$ & & $.607 * *$ & \\
\hline Item 7 & $.304 * *$ & & $.382 * *$ & & $.369 * *$ & \\
\hline Item 9 & $.776^{* *}$ & & $.786^{* *}$ & & $.774 * *$ & \\
\hline Item 2 & & $.846^{* *}$ & & $.814 * *$ & & $.811 * *$ \\
\hline Item 4 & & $.384 * *$ & & $.461 * *$ & & $.456 * *$ \\
\hline Item 6 & & $.448 * *$ & & $.532 * *$ & & $.527 * *$ \\
\hline Item 8 & & $.820 * *$ & & $.763 * *$ & & $.759 * *$ \\
\hline Item 10 & & $.447 * *$ & & $.386^{* *}$ & & $.381 * *$ \\
\hline
\end{tabular}

Note. $\lambda$ : Factor loading; Although the unstandardized values are equal across groups as a result of the equality constraints imposed on them, the standardized values still demonstrate minor group-differences as a result of the variability within each group.; $* * p<.01$ 


\section{Table S11}

Goodness-of-Fit Statistics for the Hierarchical Models Estimated on the Interpersonal Behaviors Questionnaire

\begin{tabular}{|c|c|c|c|c|c|c|}
\hline Model & $\chi^{2}$ & df & CFI & TLI & RMSEA & $\begin{array}{l}\text { RMSEA } 90 \% \\
\text { CI }\end{array}$ \\
\hline \multicolumn{7}{|l|}{ Study 1} \\
\hline Model 8.2. H-CFA: Two S-factors ( $\mathrm{Su}, \mathrm{Th}$ ) and one $\mathrm{HO}$-factor $(\mathrm{Nu})$ & $1380.047 *$ & 250 & .867 & .853 & .077 & $.073-.080$ \\
\hline Model 9.2. H-ESEM: Two S-factors (S, Fr) and one HO-factor $(\mathrm{Nu})$ & $1373.363^{*}$ & 228 & .865 & .836 & .081 & $.077-.085$ \\
\hline Model 10.2. H-CFA: Three S-factors (A, C, R) and one HO-factor (Nu) & $1611.460 *$ & 249 & .839 & .822 & .084 & $.080-.088$ \\
\hline Model 11.2. H-ESEM: Three S-factors (A, C, R) and one HO-factor (Nu) & $721.784 *$ & 207 & .939 & .919 & .057 & $.052-.061$ \\
\hline Model 12.2. H-CFA: Three S-factors (A, C, R) and two HO-factors (Su, Th) & - & - & - & - & - & - \\
\hline Model 13.2. H-ESEM: Three S-factors (A, C, R) and two HO-factors (Su, Th) & - & - & - & - & - & . \\
\hline Model 14.2. H-CFA: Six S-factors (A-Su, A-Th, C-Su, C-Th, R-Su, R-Th) and one & 953.998* & 246 & .916 & .906 & .061 & $.057-.065$ \\
\hline Model 15.2. H-ESEM: Six S-factors (A-Su, A-Th, C-Su, C-Th, R-Su, R-Th) and one HO-factor (Nu) & $243.629 *$ & 156 & .990 & .982 & .027 & $.020-.033$ \\
\hline Model 16.2. H-CFA: Six S-factors (A-Su, A-Th, C-Su, C-Th, R-Su, R-Th) and two HO-factors (Su, Th) & $805.943 *$ & 245 & .934 & .925 & .054 & $.050-.059$ \\
\hline $\begin{array}{l}\text { Model 17.2. H-ESEM: Six S-factors (A-Su, A-Th, C-Su, C-Th, R-Su, R-Th) and two HO-factors (Su, } \\
\text { Th) }\end{array}$ & $235.120^{*}$ & 155 & .991 & .983 & .026 & $.019-.032$ \\
\hline \multicolumn{7}{|l|}{ Study 2} \\
\hline Model 8.2. H-CFA: Two & $1717.058^{*}$ & 250 & .816 & .797 & .089 & $.085-.093$ \\
\hline Model 9.2. H-ESEM: Two S-factors ( $\mathrm{S}, \mathrm{Fr})$ and one $\mathrm{HO}$-factor $(\mathrm{Nu})$ & $1259.367 *$ & 228 & .871 & .844 & .078 & $.074-.082$ \\
\hline Model 10.2. H-CFA: Three S-factors (A, C, R) and one HO-factor (Nu) & $1376.752 *$ & 249 & .859 & .843 & .078 & $.074-.082$ \\
\hline Model 11.2. H-ESEM: Three S-factors (A, C, R) and one HO-factor (Nu) & $758.109 *$ & 207 & .931 & .908 & .060 & $.055-.065$ \\
\hline Model 12.2. H-CFA: Three S-factors (A, C, R) and two HO-factors ( $\mathrm{Su}, \mathrm{T}]$ & - & - & - & - & - & - \\
\hline Model 13.2. H-ESEM: Three S-factors (A, C, R) and two HO-factors (Su, Th) & - & - & - & - & - & - \\
\hline Model 14.2. H-CFA: Six S-factors (A-Su, A-Th, C-Su, C-Th, R-Su, R-Th) and one HO-factor (Nu) & $850.486 *$ & 246 & .924 & .915 & .058 & $.053-.062$ \\
\hline Model 15.2. H-ESEM: Six S-factors (A-Su, A-Th, C-Su, C-Th, R-Su, R-Th) and one HO-factor (Nu & $255.132 *$ & 156 & .988 & .978 & .029 & $.023-.036$ \\
\hline Model 16.2. H-CFA: Six S-factors (A-Su, A-Th, C-Su, C-Th, R-Su, R-Th) and two HO-factors ( $\mathrm{Su}, \mathrm{Th}$ ) & $830.813^{*}$ & 245 & .927 & .917 & .057 & $.053-.061$ \\
\hline $\begin{array}{l}\text { Model 17.2. H-ESEM: Six S-factors (A-Su, A-Th, C-Su, C-Th, R-Su, R-Th) and two HO-factors (Su, } \\
\text { Th) }\end{array}$ & $250.258 *$ & 155 & .988 & .979 & .029 & $.022-.035$ \\
\hline
\end{tabular}

Note CFA: Confirmatory factor analysis; ESEM: Exploratory structural equation modeling; B: Bifactor model; Nu: Global need nurturing behaviors; $\mathrm{Su}$ : Need supportive behaviors; Th: Need thwarting behaviors; A: Autonomy; C: Competence; R: Relatedness; HO-factor: Higher-order factor estimated as part of a higher-order model; S-factor: Specific factor estimated as part of a higher-order model; $\chi^{2}$ : Robust chi-square test of exact fit; df: Degrees of freedom; CFI: Comparative fit index; TLI: Tucker-Lewis index; RMSEA: Root mean square error of approximation; 90\% CI: 90\% confidence interval of the RMSEA; * $p<0.01$. 